\title{
A General Model for Biofilm-Driven Microbial Electrosynthesis of Carboxylates From $\mathrm{CO}_{2}$
}

\author{
Oriol Cabau-Peinado, Adrie J. J. Straathof and Ludovic Jourdin* \\ Department of Biotechnology, Faculty of Applied Sciences, Delft University of Technology, Delft, Netherlands
}

Up to now, computational modeling of microbial electrosynthesis (MES) has been underexplored, but is necessary to achieve breakthrough understanding of the processlimiting steps. Here, a general framework for modeling microbial kinetics in a MES reactor is presented. A thermodynamic approach is used to link microbial metabolism to the electrochemical reduction of an intracellular mediator, allowing to predict cellular growth and current consumption. The model accounts for $\mathrm{CO}_{2}$ reduction to acetate, and further elongation to $\mathrm{n}$-butyrate and $\mathrm{n}$-caproate. Simulation results were compared with experimental data obtained from different sources and proved the model is able to successfully describe microbial kinetics (growth, chain elongation, and product inhibition) and reactor performance (current density, organics titer). The capacity of the model to simulate different system configurations is also shown. Model results suggest $\mathrm{CO}_{2}$ dissolved concentration might be limiting existing MES systems, and highlight the importance of the delivery method utilized to supply it. Simulation results also indicate that for biofilm-driven reactors, continuous mode significantly enhances microbial growth and might allow denser biofilms to be formed and higher current densities to be achieved.

Chinese Academy of Sciences (CAS),

China

Frauke Kracke,

Stanford University, United States

${ }^{*}$ Correspondence:

Ludovic Jourdin

I.jourdin@tudelft.n

Specialty section:

This article was submitted to

Microbiotechnology,

a section of the journal

Frontiers in Microbiology

Received: 18 February 2021

Accepted: 10 May 2021

Published: 04 June 2021

Citation:

Cabau-Peinado O, Straathof AJJ and Jourdin L (2021) A General Model for Biofilm-Driven Microbial Electrosynthesis of Carboxylates From

$\mathrm{CO}_{2}$. Front. Microbiol. 12:669218.

doi: 10.3389/fmicb.2021.669218

Keywords: microbial electrosynthesis, bioelectrochemical system, microbial kinetics, mathematical model, $\mathrm{CO}_{2}$ reduction, chain elongation

\section{INTRODUCTION}

Microbial electrosynthesis (MES) is based on the use of microorganisms that can reduce $\mathrm{CO}_{2}$ to industrially relevant products (i.e., alcohols, carboxylic acids) by using electrons coming from a solid-state electrode (Lovley and Nevin, 2013; Jourdin and Strik, 2017; Kerzenmacher, 2017). MES is a promising technology to satisfy the growing demand for commodity and specialty chemicals, and has the potential to increase the value of the electrical energy produced from renewable sources (Lewis and Nocera, 2006). Until now, research on MES has been primarily focused on developing the technology by means of studying its fundamentals (e.g., electron transfer mechanisms, metabolic routes used for reducing $\mathrm{CO}_{2}$ ) and improving the efficiency of crucial components (e.g., microorganisms, cathode structure, and material) (Jourdin and Burdyny, 2020; Prévoteau et al., 2020). Even though significant progress has been achieved on these aspects, MES technology still needs to be pushed to higher performance to reach industrial viability (Jourdin et al., 2020). In that sense, rate-limiting steps, scalability, and system optimization are key aspects that need to be assessed. Initial work in all those directions has been published in the last decade (Giddings et al., 2015; Alqahtani et al., 2018; Enzmann et al., 2019; Rosa et al., 2019), but progress has been modest. 
MES is a complex system that combines both electrochemistry and biotechnology. When trying to improve reactor performance, all physical, chemical, and biological processes occurring simultaneously have to be properly regulated. A major breakthrough would require a deeper understanding of this inherent complexity. To that end, computational models are a systematic approach that can be used for testing hypotheses and obtain knowledge on the described system, as pointed out by Korth and Harnisch (2017) in their detailed review on modeling microbial electrosynthesis.

When looking at the biocatalyst itself, metabolic modeling allows for an in-depth analysis of the molecular and biochemical mechanisms occurring within a particular microorganism. These complex mathematical expressions encompass all major metabolic pathways, and simulate them in perspective of the entire metabolic network. Pandit and Mahadevan (2011) used flux balance analysis to develop one of the first computational genome-scale metabolic models, and used it to characterize the role of bioelectrosynthesis in chemical production. Their model was based on the genome of Escherichia coli, and showed that trade-offs between improving growth rates and yields could exist. Kracke and Krömer (2014) used elementary mode analysis to create multiple core networks of metabolic carbon pathways, and found that the yield obtained with electrical enhancement depends strongly on the electron transport mechanism. Marshall et al. (2017) constructed three full genome-scale metabolic models that in combination with flux balance analysis, allowed them to predict the metabolic activity of different microbial communities. Their results identified the main metabolic pathways in those systems, as well as demonstrating the possibility of multiple species being active within a very limited space near an electrode. Metabolic network models are of great use when exploring suitable MES processes, as well as when studying the pathways present within a particular microorganism. However, these are complex mathematical expressions that require prior knowledge on the genome and transcriptome of the studied organism. Moreover, data on interactions between species in mixed microbial culture biofilms, biofilm structure, and mass transport phenomena are needed when extrapolating results to a biofilm superstructure. Since this information is largely unknown in MES to date, and metabolic models are mostly focused on microbial cells and their immediate surroundings, these models are hardly suited for a more generalized study at a reactor scale.

To date, few modeling studies have been published on microbial electrosynthesis and the dynamics between microorganisms and operating conditions. Kazemi et al. (2015) modeled a biofilm-based MES cathode with a pure culture producing acetate using a conductive biofilm approach. The model allowed them to study current density and biofilm thickness on different $\mathrm{CO}_{2}$ concentrations and applied cathodic potentials. Their model showed that high $\mathrm{CO}_{2}$ concentrations decreased coulombic efficiency, while a higher cathodic potential increased the coulombic efficiency. Gadkari et al. (2019) performed a study of the interdependence of some operating parameters in a MES system using a bioanode. They developed a two-chamber model with two cell populations, allowing them to analyze the effect of parameters such as initial substrate concentration and operation cycle time on MES performance. Their results showed that reducing the operation cycle time favored production rates, but decreased substrate utilization and coulombic efficiency. Abel and Clark (2020) very recently modeled a biomass-producing system that reduces $\mathrm{CO}_{2}$ into formate electrochemically, which is then used aerobically by planktonic cells to grow. They were able to study the dynamics between $\mathrm{CO}_{2}, \mathrm{O}_{2}$, and biomass growth as well as the influence of some operational parameters on the general performance of the reactor. $\mathrm{O}_{2}$ and $\mathrm{CO}_{2}$ mass transfer were found to be limiting the formate-mediated reactor. Their study also indicates that gas recycling to increase overall $\mathrm{CO}_{2}$ utilization will be necessary when scaling-up these systems. Salimijazi et al. (2020) also very recently developed a mathematical model to determine the maximum theoretical efficiency of MES processes from electrical power to biofuels. They predicted that by using highly engineered microorganisms, the conversion efficiency to biofuels could increase up to $52 \%$. Their study also shows an interdependence between said efficiency, and biofilm thickness and resistivity. To maintain a given efficiency, if a biofilm resistivity increases its thickness must decrease, while increasing its area.

The use of computational modeling of MES at reactor scale for process understanding and system optimization has clearly been underexplored. Previous modeling papers mainly focused on studying the effects of operational parameters on the general performance of specific MES processes. Moreover, one of the main knowledge gaps in MES is that microbial growth rates and microbial kinetics have not been experimentally elucidated and are thus unknown to date. To achieve a higher process performance, a deeper understanding on the microbial metabolism and production kinetics is necessary. In addition, the study of how microorganisms adapt to changing operational parameters and to different reactor environments (i.e., changing substrate and/or product concentrations) is of crucial importance when elucidating what is limiting MES performance. A general black-box mathematical model allowing for the dynamic description of attached microbial cells, and their interactions with the cathode can help to study such complex environments and potentially elucidate current process bottlenecks. To this end, the objective of this work was to develop a reactor-scale mathematical modeling framework for the study of biofilm-driven microbial electrosynthesis processes with multiple product spectrum and different operational conditions, i.e., batch or continuous mode, continuous or discontinuous $\mathrm{CO}_{2}$ supply. To achieve this, a dynamic black-box model of a MES reactor for the reduction of $\mathrm{CO}_{2}$ including microbial kinetics with product inhibition and integrated chain elongation, was implemented and solved with the MATLAB software package (MATLAB 2019b).

Since microbial kinetics in MES are not yet available, the biofilm-driven reactor from Jourdin et al. (2019) is used to fit the model and estimate the unknown kinetic parameters. The model is then applied to and validated with experimental data obtained from other studies. First, the capacity of the model 
A

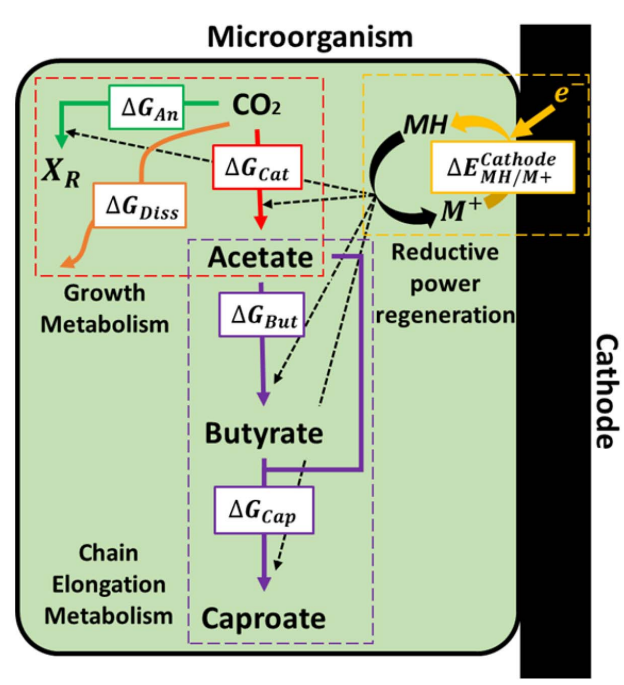

B

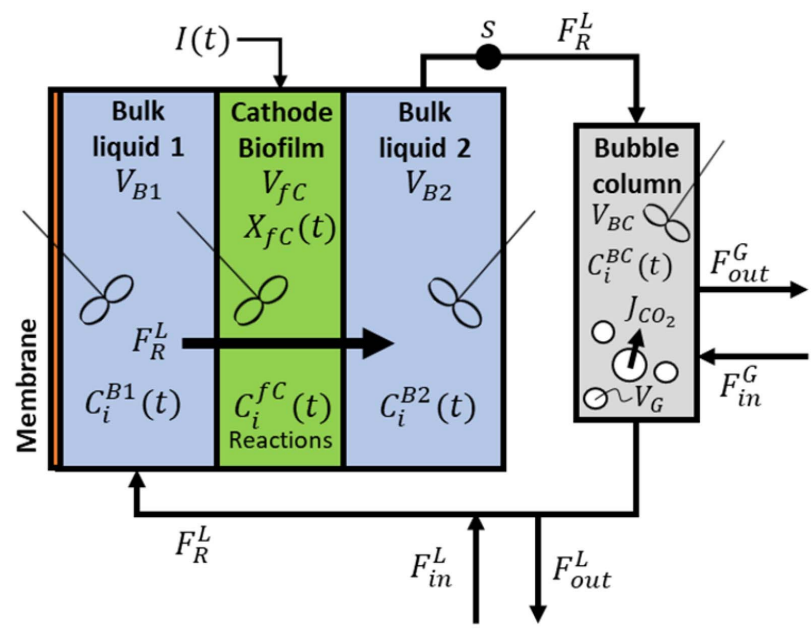

FIGURE 1 | (A) Biological and electrochemical reactions occurring within a single cell. The energy generated during the reduction of carbon dioxide (catabolism) is used for biomass formation (anabolism), butyrate and caproate formation (chain elongation), and partly dissipated as heat. The reductive power is regenerated in the bioelectrochemical reduction of the oxidized mediator $\mathrm{M}^{+}$and the excess of reduced mediator is used in the chain elongation metabolism. (B) Model domains of the continuous reactor based on Jourdin et al. (2019). $\mathrm{CO}_{2}$ is supplied in the external bubble column during liquid recirculation and the catholyte is forced through a porous biocathode.

to successfully predict different operational conditions is shown by simulating the system from Jourdin et al. (2018). In this first simulation, the same reactor but operated under different dilution rates and feeding strategies is evaluated. Afterward, since not all reported MES reactors reach chain elongation and more than $75 \%$ of all MES studies have reported only acetate production (Flexer and Jourdin, 2020), the ability of the model to simulate different product spectrum is also shown. For this purpose, the experimental data from the batch reactor used in Marshall et al. (2013) is used for validation.

\section{MODEL DESCRIPTION}

\section{System Overview}

The model consists of a bioelectrochemical reactor with multiple domains encompassing all subsequent mass balance equations, as well as all electrochemical and biological kinetic reactions. The four domains of the system modeled to simulate reactors from Jourdin et al. are shown in Figure 1B, namely the gas/liquid mass transfer compartment, the cathode biofilm, and both bulk liquid compartments on either side of the cathode/biofilm. The two domains of the modeled reactor from Marshall et al. can be found in Supplementary Figure 1 in the Supplementary Information 1.1. All symbols used and their respective units can be found in the main text in Table $\mathbf{1}$ and in the Supplementary Information 1.2. Assumptions for all cases are:

- The biofilm is a continuous phase, thus different microbial species and their distribution are neglected.

- All reactions occur in the biofilm only. Reactions occurring in the bulk liquid are neglected, as the prevalence of the biofilm over suspended cells was demonstrated on their investigation.

- Electrical resistances of the catholyte and the biofilm matrix can be neglected.

- Volumes of all compartments are constant.

- All liquid compartments are well mixed.

- The biofilm domain is also well-mixed (no concentration gradients, see section "Model Assumptions Evaluation").

- Microorganisms accumulate in the biofilm domain and do not flow out (detachment from the biofilm is neglected).

- $\mathrm{pH}$, electrical potential, and temperature are strictly controlled.

Simulations were performed with a set of mass balances including the exchange rate (flow in and out) from the continuous operation, the net rate of reactions in the biofilm, and the gas/liquid transfer of $\mathrm{CO}_{2}$ (in detail in Supplementary Information 1.2). The gas/liquid mass transfer from the gas to the liquid phase was modeled with the overall gas/liquid mass transfer coefficient $\left(k_{L} a\right)$. It is possible to simulate reactors with different geometries, cathode properties or cell cultures modifying the obtained mass balance equations.

A general scheme of the microbial catalyst, with all the relevant biological and electrochemical reactions is depicted in Figure 1A, and further described in sections "Electrochemical Reactions""Biological Reactions" (Figure 1).

\section{Electrochemical Reactions \\ Electron Transfer From Cathode to an Intracellular Electron Mediator}

In microbial electrosynthesis, electrons must be transferred from the surface of the cathode to the intracellular space of 
the microorganism likely via multiple transmembrane redox centers (e.g., cytochromes) (Morgado et al., 2012). This redox protein chain leads to the reduction of an intracellular redox mediator, which is then used by the microorganism in its metabolism (Hamelers et al., 2011). For simplicity purposes and since intermediate processes are not expected to be limiting the electrochemical rate, the electron transfer between the cathode and the microorganism was assumed to occur by the direct reduction of an oxidized mediator species $\left(\mathrm{M}^{+}\right)$:



The electrochemical rate $r_{M}^{e l e c}\left(m_{0} l_{M^{+}} m_{f c}^{-3} s^{-1}\right)$ for Eq. 1 is obtained with the Butler-Volmer equation (Eq. 2). This general model has been successful in the modeling of heterogeneous electron transfer between microorganisms and electrode in microbial fuel cell processes (Zeng et al., 2010; Hamelers et al., 2011).

$$
r_{M}^{\text {elec }}=k_{e}^{f} C_{M^{+}} C_{H^{+}}-k_{e}^{r} C_{M H}
$$

The electrochemical rate coefficients, which account for the electrical potential of the electrode and the mediator, $k_{e}^{f}$ (Eq. 3)

\begin{tabular}{|c|c|c|c|c|}
\hline Parameter & Symbol & Case value & Units & Source \\
\hline Standard Gibbs energy of dissipation for $\mathrm{CO}_{2}$ & $\triangle G_{\text {Diss }}^{\mathrm{CO}_{2}}$ & 1076 & $\mathrm{~kJ} / \mathrm{mol}_{x}$ & [a] \\
\hline Half-saturation constant for $\mathrm{CO}_{2}$ & $\mathrm{~K}_{\mathrm{CO}_{2}}$ & 3.8 & $\mathrm{~mol} / \mathrm{m}^{3}$ & [c] \\
\hline Half-saturation constant for $\mathrm{NH}_{4}{ }^{+}$ & $\mathrm{K}_{\mathrm{NH}_{4}}$ & 0.05 & $\mathrm{~mol} / \mathrm{m}^{3}$ & [d] \\
\hline Half-saturation constant for $\mathrm{MH}$ & $K_{\mathrm{MH}}$ & 0.1 & $\mathrm{~mol} / \mathrm{m}^{3}$ & [b] \\
\hline Half-saturation constant for Butyrate & $K_{\text {But }}$ & 0.076 & $\mathrm{~mol} / \mathrm{m}^{3}$ & {$[f]$} \\
\hline Critical concentration for Acetate & $C_{\mathrm{AC}}^{*}$ & 800 & $\mathrm{~mol} / \mathrm{m}^{3}$ & [g] \\
\hline Critical concentration for Butyrate & $C_{\text {But }}^{*}$ & 285 & $\mathrm{~mol} / \mathrm{m}^{3}$ & {$[\mathrm{~h}]$} \\
\hline Critical concentration for Caproate & $C_{\text {Cap }}^{*}$ & 170 & $\mathrm{~mol} / \mathrm{m}^{3}$ & [i] \\
\hline \multicolumn{5}{|l|}{ Electrochemical kinetics } \\
\hline Standard heterogeneous electron transfer rate & $k_{e}^{0}$ & 0.03 & $1 / s$ & [j] \\
\hline Number of electrons transferred & $\mathrm{n}$ & 2 & $\mathrm{~mol}_{e-} / \mathrm{mol}_{\left(\mathrm{M}^{*} / \mathrm{MH}\right)}$ & From Eq. 1 \\
\hline \multicolumn{5}{|l|}{ Bulk liquid } \\
\hline Bulk liquid volume & $V_{T}^{C}$ & 370 & $\mathrm{~mL}$ & {$[\mathrm{~m}]$} \\
\hline Bubble column volume & $V_{\mathrm{BC}}$ & 280.9 & $\mathrm{~mL}$ & {$[\mathrm{~m}]$} \\
\hline Dilution rate & $D_{R}^{L}$ & Variable & $1 / d$ & {$[\mathrm{~m}]$} \\
\hline $\mathrm{H}^{+}$concentration & $C_{H^{+}}^{\mathrm{B}}$ & $10^{-5.8}$ & $\mathrm{~mol} / \mathrm{L}$ & {$[\mathrm{m}]$} \\
\hline Gas-liquid mass transfer coefficient & $k_{L} a$ & 2.5 & $1 / \mathrm{h}$ & Calculated from [m] \\
\hline \multicolumn{5}{|l|}{ Initial concentrations } \\
\hline Carbon dioxide & $\mathrm{C}_{\mathrm{CO}_{2}}^{0}$ & 0 & $\mathrm{~mol} / \mathrm{m}^{3}$ & {$[\mathrm{~m}]$} \\
\hline Acetate & $C_{\mathrm{Ac}}^{0}$ & 30 & $\mathrm{~mol} / \mathrm{m}^{3}$ & {$[\mathrm{~m}]$} \\
\hline Butyrate & $C_{\text {But }}^{0}$ & 0 & $\mathrm{~mol} / \mathrm{m}^{3}$ & {$[\mathrm{~m}]$} \\
\hline Universal gas constant & $R$ & 8.31 & $\mathrm{~J} /(\mathrm{mol} \mathrm{K})$ & \\
\hline Standard temperature & $T_{0}$ & 298 & K & \\
\hline Working temperature & $T$ & 305 & K & {$[\mathrm{m}]$} \\
\hline
\end{tabular}

TABLE 1 | Input parameters used in the fitting of the model with their symbols, values, and units.

[a] Heijnen and Van Dijken (1992), [b] Korth et al. (2015), [c] Nielsen et al. (2019), [d] Pérez et al. (2005), [e] Wiesenborn et al. (1988), [f] Ahring and Westermann (1987), [g] Klemps et al. (1987), [h] Zheng and Yu (2005), [i] Roghair et al. (2018), [j] Ly et al. (2013), [k] Hamelers et al. (2011), [I] Dubouchaud et al. (2018), [m] Jourdin et al. (2019). 
and $k_{e}^{r}$ (Eq. 4) are:

$$
\begin{gathered}
k_{e}^{f}=k_{e}^{0} \exp \left[-\alpha \frac{n F}{R T}\left(E_{C}-E_{M}\right)\right] \\
k_{e}^{r}=k_{e}^{0} \exp \left[(1-\alpha) \frac{n F}{R T}\left(E_{C}-E_{M}\right]\right.
\end{gathered}
$$

To date, the exact mechanism for extracellular electron transfer (EET) is largely unknown. A wide range of different mechanisms has been investigated, from direct electron transfer (Nevin et al., 2010, 2011) to mediated processes (Blanchet et al., 2015; Jourdin et al., 2016). The electron transfer mechanism can be highly dependent on the type of system being studied, hence the aforementioned mathematical expressions were chosen as they allow to mimic different EET mechanisms by adjusting the electrode and the mediator potentials.

\section{Current Density}

The transfer of electrons from cathode to microorganism results in the observed electric current. This current is determined by a balance between the electrochemical reaction rate $r_{M}^{\text {elec }}$ (Eq. 2) and the biological conversion rate. In the present model, the current at the cathode is given by the electrochemical reduction of the redox mediator (Eq. 5). Since the electrochemical rate is defined per biofilm volume, a correction to account for the volume of the biocathode $\left(V_{f c}\right)$ domain is included.

$$
I=n F r_{M}^{e l e c} V_{f c}
$$

\section{Biological Reactions Microbial Metabolism}

Acetate originates from $\mathrm{CO}_{2}$, but the pathways for butyrate and caproate production in MES systems are largely unknown. Acetate elongation can occur via multiple pathways, including or not carbon dioxide utilization (Raes et al., 2017; Jourdin et al., 2018; Vassilev et al., 2018). In addition, ethanol has been hypothesized to act as electron donor for the elongation of acetate into longer carboxylates (Ganigué et al., 2015; BatlleVilanova et al., 2017; Vassilev et al., 2018). Owing to the high complexity of mixed microbial communities, simplifications are needed when trying to model such environments. The present study approaches this simplification by encompassing all major metabolisms from different cells into one hypothetical black box organism. However, the addition of solventogenesis and chain elongation to the general growth metabolism would require prior knowledge of the exact ratios at which acetate, butyrate, caproate, and ethanol are produced (Heijnen and Van Dijken, 1992; Kleerebezem and Van Loosdrecht, 2010). Since these ratios are not known, the metabolism of the modeled organism can be separated into four different steps, i.e., 1) the energy-generating catabolic reaction, 2) the energy-consuming anabolic reaction for biomass production, 3) the chain elongation metabolism, and 4) the electrochemical regeneration of the reductive power (Figure 1A). The use of a thermodynamic approach allows to account only for end products of the metabolism, bypassing intermediates like ethanol. Hence, for modeling purposes and since this information is currently not available for MES processes, a $\mathrm{CO}_{2}$-independent acetate and butyrate elongation pathway not linked to growth is hypothesized. The model includes reaction rates for $\mathrm{CO}_{2}$, acetate, butyrate, and caproate. Including reaction rates for compounds that have not been detected would lead to additional kinetic parameters, and these would be unidentifiable. The studies used in this work for parameter fitting and model validation did not detect ethanol or propionate, for example, so reaction rates for these compounds are not included here. To model studies that did measure concentrations of these compounds, model extension is needed.

The general growth stoichiometry of the proposed bacteria is then calculated following a thermodynamic state analysis (Kleerebezem and Van Loosdrecht, 2010). From an energetic point of view, acetate is produced from carbon dioxide to generate energy for all the other reactions occurring within the cell $\left(\triangle G_{\text {Cat }}\right)$. A part of that energy is used for butyrate $\left(\triangle G_{\text {But }}\right)$ and caproate $\left(\triangle G_{\text {Cap }}\right)$ production, as well as for biomass growth and cell maintenance reactions $\left(\triangle G_{\mathrm{An}}\right)$, whereas the rest is dissipated as heat $\left(\triangle G_{D i s s}\right)$. The biomass formula is assumed to be $\mathrm{CH}_{1.8} \mathrm{O}_{0.5} \mathrm{~N}_{0.2}$ (Roels, 1983; Battley, 1987). The catabolic microbial reaction for carbon dioxide reduction to acetate (Eq. 6) and the anabolic reaction for growth (Eq. 7) can be written as follows:

$$
\begin{gathered}
2 \mathrm{CO}_{2}+4 \mathrm{MH}+3 \mathrm{H}^{+}=\mathrm{CH}_{3} \mathrm{COO}^{-}+4 \mathrm{M}^{+}+2 \mathrm{H}_{2} \mathrm{O} \\
\mathrm{CO}_{2}+2.1 \mathrm{MH}+0.2 \mathrm{NH}_{4}^{+}+1.9 \mathrm{H}^{+}= \\
\mathrm{CH}_{1.8} \mathrm{O}_{0.5} \mathrm{~N}_{0.2}+2.1 \mathrm{M}^{+}+1.5 \mathrm{H}_{2} \mathrm{O}
\end{gathered}
$$

As explained previously, ethanol is not included in the elongation metabolism of the proposed bacteria and the reductive power is assumed to directly come from the redox mediator $\mathrm{MH}$. Then, acetate (Eq. 8) and butyrate (Eq. 9) elongation reactions are described as:

$$
2 \mathrm{CH}_{3} \mathrm{COO}^{-}+2 \mathrm{MH}+3 \mathrm{H}^{+}=\mathrm{C}_{3} \mathrm{H}_{7} \mathrm{COO}^{-}+2 \mathrm{M}^{+}+2 \mathrm{H}_{2} \mathrm{O}
$$

$$
\begin{aligned}
& \mathrm{CH}_{3} \mathrm{COO}^{-}+\mathrm{C}_{3} \mathrm{H}_{7} \mathrm{COO}^{-}+2 \mathrm{MH}+3 \mathrm{H}^{+}= \\
& \mathrm{C}_{5} \mathrm{H}_{11} \mathrm{COO}^{-}+2 \mathrm{M}^{+}+2 \mathrm{H}_{2} \mathrm{O}
\end{aligned}
$$

The Gibbs energies of reaction $\Delta G_{\mathrm{Cat}}^{0}, \Delta G_{\mathrm{An}}^{0}, \Delta G_{\mathrm{But}}^{0}$ and $\triangle G_{\text {Cap }}^{0}$ are calculated using the values for the energy of formation obtained from Kleerebezem and Van Loosdrecht (2010), and adapted to reactor conditions (Supplementary Information 1.3). In this model, the mediator couple $\mathrm{MH} / \mathrm{M}^{+}$is the only redox mediator species that limit the rate of the redox reactions of the modeled microorganism. The Gibbs energy of formation for this pair was estimated from the standard redox potential and adapted to reactor conditions, as described by Korth et al. (2015). In this study, the standard redox potential of NADH/NAD ${ }^{+}$was chosen (in detail in the Supplementary Information 1.4).

The catabolic rate $\left(\lambda_{\mathrm{Cat}}\right)$ is a factor representing how many times the catabolic reaction must occur to supply enough energy 
for the anabolic, elongation, and dissipation reactions. Using a dissipation energy for chemoautotrophic $\mathrm{CO}_{2}$ reducing processes of $\triangle G_{\text {Diss }}^{C O_{2}}=1076 \mathrm{~kJ} \mathrm{~mol}_{X}^{-1}$ (Heijnen and Van Dijken, 1992), the catabolic rate (Eq. 10) is calculated:

$$
\lambda_{\text {Cat }}=\frac{\Delta G_{\text {Diss }}^{\mathrm{CO}_{2}}+\Delta G_{\mathrm{An}}}{-\triangle G_{\mathrm{Cat}}+Y_{\mathrm{Ac}}^{\text {But }} \triangle G_{\mathrm{But}}+Y_{\mathrm{Ac}}^{\mathrm{Cap}} \triangle G_{\mathrm{Cap}}}
$$

The thermodynamic yields $Y_{\mathrm{Ac}}^{B u t}$ and $Y_{\mathrm{Ac}}^{\mathrm{Cap}}$ are calculated as the ratio between the energies of formation of both butyrate and caproate over acetate. The growth stoichiometry $\left(Y_{i}^{M e t}\right)$ is then obtained by combining both catabolic and anabolic reactions (Eq. 6 and Eq. 7) as $\lambda_{C a t} Y_{i}^{C a t}+Y_{i}^{A n}$, resulting in the following general metabolic reaction (Eq. 11):

$$
\begin{aligned}
& -Y_{\mathrm{CO}_{2}}^{\mathrm{Met}} \mathrm{CO}_{2}-\mathrm{Y}_{\mathrm{MH}}^{\mathrm{Met}} \mathrm{MH}-\mathrm{Y}_{\mathrm{NH}_{4}^{+}}^{\mathrm{Met}} \mathrm{NH}_{4}^{+}-\mathrm{Y}_{\mathrm{H}^{+}}^{\mathrm{Met}} \mathrm{H}^{+}+\mathrm{Y}_{\mathrm{X}}^{\mathrm{Met}} \\
& \mathrm{CH}_{1.8} \mathrm{O}_{0.5} \mathrm{~N}_{0.2}+\mathrm{Y}_{\mathrm{Ac}}^{\mathrm{Met}} \mathrm{C}_{2} \mathrm{H}_{3} \mathrm{O}_{2}^{-}+Y_{M^{+}}^{\mathrm{Met}} \mathrm{M}^{+}+\mathrm{Y}_{\mathrm{H}_{2} \mathrm{O}}^{\mathrm{Met}} \mathrm{H}_{2} \mathrm{O}
\end{aligned}
$$

\section{Microbial Kinetic Equations}

A triple hyperbolic uptake equation accounting for both the carbon and nitrogen sources, as well as for the electron donor is used to describe the carbon dioxide specific uptake rate (Monod, 1949; Bader, 1978; Bae and Rittmann, 1996) (Eq. 12; Parameters in Table 1).

$$
q_{\mathrm{CO}_{2}}=q_{\mathrm{CO}_{2}}^{\max } \frac{C_{\mathrm{CO}_{2}}}{K_{\mathrm{CO}_{2}}+C_{\mathrm{CO}_{2}}} \frac{C_{\mathrm{NH}_{4}^{+}}}{K_{\mathrm{NH}_{4}^{+}}+C_{\mathrm{NH}_{4}^{+}}} \frac{C_{\mathrm{MH}}}{K_{\mathrm{MH}}+C_{\mathrm{MH}}}
$$

The maintenance coefficient on $\mathrm{CO}_{2}$ for anaerobic microorganisms, $m_{\mathrm{CO}_{2}} \quad\left(m_{\mathrm{CO}_{2}} \quad m_{\mathrm{X}} \mathrm{l}_{\mathrm{X}}^{-1} h^{-1}\right)$ is estimated with a temperature dependent Arrhenius-type equation (Eq. 13) (Tijhuis et al., 1993). The specific biomass growth rate $\mu\left(h^{-1}\right)$ can then be described as a function of the carbon dioxide uptake and maintenance rates (Eq. 14).

$$
\begin{gathered}
m_{\mathrm{CO}_{2}}=\frac{3.3}{\triangle G_{\mathrm{Cat}}} \exp \left[\frac{-69.4}{R}\left(\frac{1}{T}-\frac{1}{T_{0}}\right)\right] \\
\mu=\frac{q \mathrm{CO}_{2}+m_{\mathrm{CO}_{2}}}{Y_{\mathrm{CO}_{2}}^{M e t}}
\end{gathered}
$$

The specific elongation rates for butyrate and caproate production are then described using double and triple hyperbolic uptake equations, respectively. Jourdin et al. (2018) described a threshold concentration of acetate necessary for chain elongation to occur. A follow-up study suggested that also a threshold concentration of butyrate for caproate production might exist (Jourdin et al., 2019). To incorporate these threshold values into the model, the method proposed by Ribes et al. (2004) is applied to the hyperbolic specific uptake rates for both acetate (Eq. 15) and butyrate (Eq. 16).

$$
q_{\mathrm{But}}^{\text {elong }}=q_{\mathrm{But}}^{\max } \frac{C_{\mathrm{Ac}}-C_{\mathrm{Ac}}^{t} w_{\mathrm{Ac}}}{K_{\mathrm{Ac}}+C_{\mathrm{Ac}}-C_{\mathrm{Ac}}^{t} w_{\mathrm{Ac}}} Z_{\mathrm{Ac}} \frac{C_{\mathrm{MH}}}{K_{\mathrm{MH}}+C_{\mathrm{MH}}}
$$

$$
\begin{aligned}
& q_{\mathrm{Cap}}^{\text {elong }}=q_{\mathrm{Cap}}^{\max } \frac{C_{\mathrm{Ac}}-C_{\mathrm{Ac}}^{t} w_{\mathrm{Ac}}}{K_{\mathrm{Ac}}+C_{\mathrm{Ac}}-C_{\mathrm{Ac}}^{t} w_{\mathrm{Ac}}} \\
& Z_{\mathrm{Ac}} \frac{C_{\mathrm{But}}-C_{\mathrm{But}}^{t} w_{\mathrm{But}}}{K_{\mathrm{But}}+C_{\mathrm{But}}-C_{\mathrm{But}}^{t} w_{\mathrm{But}}} Z_{\mathrm{But}} \frac{C_{\mathrm{MH}}}{K_{\mathrm{MH}}+C_{\mathrm{MH}}}
\end{aligned}
$$

Where $w_{i}$ and $Z_{i}$ are empirical sigmoidal functions used to ensure the rates have a smooth increase when the concentration reaches the threshold value $C_{i}^{t}$ and to avoid negative values if the threshold is yet to be achieved (Eq. 17 and Eq. 18).

$$
\begin{aligned}
w_{i} & =\frac{1}{1+\exp \left[A_{i}\left(C_{i}^{t}-C_{i}\right)\right]} \\
Z_{i} & =\frac{1}{1+\exp \left[A_{i}\left(T_{i}-C_{i}\right)\right]}
\end{aligned}
$$

The additional tuning parameters $A_{i}$ and $T_{i}$ incorporated into the substrate uptake expressions have no biological meaning and are $10 / C_{i}^{t}$ and $1.1 C_{i}^{t}$, respectively. An elaborated discussion on how to determine these terms can be found in the original paper (Ribes et al., 2004).

The overall coupling between substrate uptake, biomass growth, maintenance, and elongation reactions for all the remaining metabolites (excluding $\mathrm{CO}_{2}$ ) is achieved by using a Herbert-Pirt relation (Eq. 19) and the general metabolic stoichiometry (Eq. 11).

$$
q_{i}=Y_{i}^{M e t} \mu-m_{\mathrm{CO}_{2}} \frac{Y_{i}^{\mathrm{Cat}}}{Y_{\mathrm{CO}_{2}}^{\mathrm{Cat}}}+Y_{i}^{\text {But }} q_{\mathrm{But}}^{\text {elong }}+Y_{i}^{\mathrm{Cap}} q_{\mathrm{Cap}}^{\text {elong }}
$$

Finally, biological rates for all chemical components are $r_{i}=$ $q_{i} C_{X}$ and $r_{X}=\mu C_{X}$ for biomass.

\section{Carboxylic Acids Inhibition}

Carboxylic acids (CAs) are known for their toxicity, which can be attributed to their acid form. The acid form is able to diffuse across the cell membrane and deprotonate in the cytoplasm, generating a $\mathrm{pH}$ gradient. In order to maintain homeostasis, cells typically have to use membrane-bound ATPases to expel the excess of protons to the outside. As more ATP is redirected to keep this gradient under control, growth and production yields are substantially decreased (Russell, 1992, 2007). Moreover, the longer the carbon chain, the higher the toxicity of the acid, since long CAs are able to damage the structure of the cell membrane (Roghair et al., 2018).

When modeling microorganisms in MES systems, it is important to account for CAs inhibition. However, product inhibition kinetics in MES remains unknown to date, hence a generalized inhibition model is preferred here. In this study, a linear model is adopted (Ghose and Tyagi, 1979). Product inhibition effect is described by the linear term $\left(1-C_{i} / C_{i}^{*}\right)$, where $C_{i}^{*}\left(\mathrm{~mol} \mathrm{~m}^{-3}\right)$ refers to the critical concentration at which the whole metabolism is halted due to the toxicity of the produced compound. Acetate, butyrate, and caproate inhibition terms are then added to the carbon dioxide uptake 
rate Eq. 12 and to the elongation rates Eq. 15 and Eq. 16 as follows:

$$
\begin{gathered}
q_{\mathrm{CO}_{2}}=q_{\mathrm{CO}_{2}}^{\max } \frac{C_{\mathrm{CO}_{2}}}{K_{\mathrm{CO}_{2}}+C_{\mathrm{CO}_{2}}} \frac{C_{\mathrm{NH}_{4}^{+}}}{K_{\mathrm{NH}_{4}^{+}}+C_{\mathrm{NH}_{4}^{+}}} \frac{C_{\mathrm{MH}}}{K_{\mathrm{MH}}+C_{\mathrm{MH}}} \\
\left(1-\frac{C_{\mathrm{Ac}}}{C_{\mathrm{Ac}}^{*}}\right)\left(1-\frac{C_{\mathrm{But}}}{C_{\mathrm{But}}^{*}}\right)\left(1-\frac{C_{\mathrm{Cap}}}{C_{\mathrm{Cap}}^{*}}\right) \\
q_{\mathrm{But}}^{\text {elong }}=q_{\mathrm{But}}^{\max } \frac{C_{\mathrm{Ac}}-C_{\mathrm{Ac}}^{t} w_{\mathrm{Ac}}}{K_{\mathrm{Ac}}+C_{\mathrm{Ac}}-C_{\mathrm{Ac}}^{t} w_{\mathrm{Ac}}} Z_{\mathrm{Ac}} \frac{C_{\mathrm{MH}}}{K_{\mathrm{MH}}+C_{\mathrm{MH}}} \\
\left(1-\frac{C_{\mathrm{Ac}}}{C_{\mathrm{Ac}}^{*}}\right)\left(1-\frac{C_{\mathrm{But}}}{C_{\mathrm{But}}^{*}}\right)\left(1-\frac{C_{\mathrm{Cap}}}{C_{\mathrm{Cap}}^{*}}\right) \\
q_{\mathrm{Cap}}^{\text {elong }}=q_{\mathrm{Cap}}^{\text {max }} \frac{C_{\mathrm{Ac}}-C_{\mathrm{Ac}}^{t} w_{\mathrm{Ac}}}{K_{\mathrm{Ac}}+C_{\mathrm{Ac}}-C_{\mathrm{Ac}}^{t} w_{\mathrm{Ac}}} Z_{\mathrm{Ac}} \frac{C_{\mathrm{But}}-C_{\mathrm{But}}^{t} w_{\mathrm{But}}}{K_{\mathrm{But}}+C_{\mathrm{But}}-C_{\mathrm{But}}^{t} w_{\mathrm{But}}} \\
Z_{\mathrm{But}} \frac{C_{\mathrm{MH}}}{K_{\mathrm{MH}}+C_{\mathrm{MH}}}\left(1-\frac{C_{\mathrm{Ac}}}{C_{\mathrm{Ac}}^{*}}\right)\left(1-\frac{C_{\mathrm{But}}}{C_{\mathrm{But}}^{*}}\right)\left(1-\frac{C_{\mathrm{Cap}}}{C_{\mathrm{Cap}}^{*}}\right)
\end{gathered}
$$

\section{Simulation and Model Fitting Procedures}

The kinetic maximum specific rates $q_{\mathrm{CO}_{2}}^{\max }$, $q_{\mathrm{But}}^{\max }$ and $q_{\mathrm{Cap}}^{\max }$ and the concentration thresholds $C_{\mathrm{Ac}}^{t}$ and $C_{\mathrm{But}}^{t}$ have not been experimentally determined in MES to date. Therefore, they were found by minimizing the residual sum of squares when fitting bulk concentrations of acetate, butyrate, and caproate over time. In this work, a residual is the difference between the experimental measurement from Jourdin et al. (2019) FTR2 reactor and the calculated value for that measurement obtained from the model. As the model is a non-linear system of equations, a nonlinear least-squares regression was used. The minimization was performed using the Nelder-Mead method as implemented in MATLAB (Table 1).

\section{RESULTS AND DISCUSSION}

\section{Model Fitting}

To obtain the necessary parameters for the kinetic equations, the model was fitted with the experimental results obtained by Jourdin et al. (2019). That system was operated in continuous mode with continuous $\mathrm{CO}_{2}$ sparging. Since the gas-liquid mass transfer coefficient $k_{L} a$ for $\mathrm{CO}_{2}$ was not reported in the original work, its value was approximated from the reported inorganic carbon concentrations and found to be of the same order of magnitude as those reported on similar sparging mechanisms, i.e., $2.5 \mathrm{~h}^{-1}$ (Bajracharya et al., 2016). The hydraulic retention time (HRT), used to determine the dilution rate, was first increased from 4 to 8 days and then from 8 to 14 days. The best fitting results are shown in Figure 2A, together with the organics concentration measured experimentally by Jourdin et al. (2019). The model is able to follow the main trend of the experimental results. For the data points, the population standard deviation of the model was $31.7 \mathrm{mmol} / \mathrm{L}$ for acetate, $14.56 \mathrm{mmol} / \mathrm{L}$ for butyrate, and $3.65 \mathrm{mmol} / \mathrm{L}$ for caproate. The simulation shows deviations that can be attributed to the previously introduced simplifications on the model, such as exclusion of the dynamics occurring within a mixed culture. No special effect of increasing the HRT can be observed. The kinetic maximum specific rates $q_{\mathrm{CO}_{2}}^{\max }$, $q_{\mathrm{But}}^{\max }$, and $q_{\mathrm{Cap}}^{\max }$ and the concentration thresholds $C_{\mathrm{Ac}}^{t}$ and $C_{\mathrm{But}}^{t}$ were found to be $-0.307 \mathrm{~mol}_{\mathrm{CO} 2} /\left(\mathrm{mol}_{x} \mathrm{~h}\right)$, $2.12 \times 10^{-2} \operatorname{mol}_{\text {But }} /\left(\operatorname{mol}_{x} \mathrm{~h}\right), 4.64 \times 10^{-3} \mathrm{~mol}_{\text {Cap }} /\left(\mathrm{mol}_{x} \mathrm{~h}\right)$, $123 \mathrm{mmol}_{\mathrm{Ac}} / \mathrm{L}$ and $43 \mathrm{mmol}_{\mathrm{But}} / \mathrm{L}$, respectively. There is a lack of reported values in MES for these kinetic parameters, hence it is difficult to assess the values obtained here. Nagarajan et al. (2013) used a $\mathrm{CO}_{2}$ specific uptake rate on the same order of magnitude as the one obtained in this study, of $-0.2 \mathrm{~mol}_{\mathrm{CO} 2} /\left(\mathrm{mol}_{x} \mathrm{~h}\right)$, when characterizing acetogenic metabolism by using a genomescale metabolic reconstruction approach; however, they failed to confirm the value experimentally (Figure 2).

The computed substrate concentrations over time (Figure 2B) show an initial decrease, with a later stabilization for $\mathrm{CO}_{2}$ and a slight increase for $\mathrm{NH}_{4}{ }^{+}$. This profile can be related to the developing cell population, with an initial exponential growth phase and a later plateauing when steady-state is reached (Figure 2C; Monod, 1949; Hwang et al., 2020). According to the model, cells use the nitrogen source for growth, whereas the carbon source is used for both growth, maintenance, and elongation reactions. The later ammonium concentration increase can then be attributed to biomass growth slowing down, and the stabilization of the carbon dioxide concentration to its continuous usage in maintenance and elongation reactions. The maximum growth rate (see Supplementary Information 2.1) was calculated to be on average $0.12 \mathrm{~d}^{-1}$ and within the range of typical reported growth rates for acetogens $\left(0.1\right.$ to $\left.0.4 \mathrm{~d}^{-1}\right)$ (Ahring and Westermann, 1987; Klemps et al., 1987).

According to the model, none of the substrates was depleted. To study which factor is mainly controlling biological rates, the kinetic hyperbolic uptake and product inhibition terms from Eq. 20, 21, and 22 are graphically depicted over time in Figure 2D. These terms can be used as indicators for metabolic limitations, being responsible for the deviations between the theoretical maximum rates and the observed ones (Chen and Hashimoto, 1980; Pavlostathis and Giraldo-Gomez, 1991; Zeng and Deckwer, 1995). During the first 100 days of the experiment, carbon dioxide was the main factor limiting microbial kinetics, with a decrease of the maximum rate of about $30 \%$. After day 100 , product inhibition became the main limiting step, especially due to high acetate and butyrate concentrations. The initial carbon dioxide limitation can be attributed to its relatively high half-saturation constant of $3.8 \mathrm{mmol} / \mathrm{L}$ (Schuchmann and Müller, 2013), resulting on a fast drop of its uptake rate even when dissolved $\mathrm{CO}_{2}$ is still far from being depleted. A combination of poor gas-liquid mass transfer and a low gas inlet $\mathrm{CO}_{2}$ partial pressure were the limiting steps during this first period. The effect of changing these input parameters is depicted in Figure 3. Increasing the $k_{L} a$ results on a higher biomass production rate, as $\mathrm{CO}_{2}$ is dissolved faster into the liquid (Figure 3A). This improvement decreases the higher the transfer coefficient. At a certain point, the rate of the 

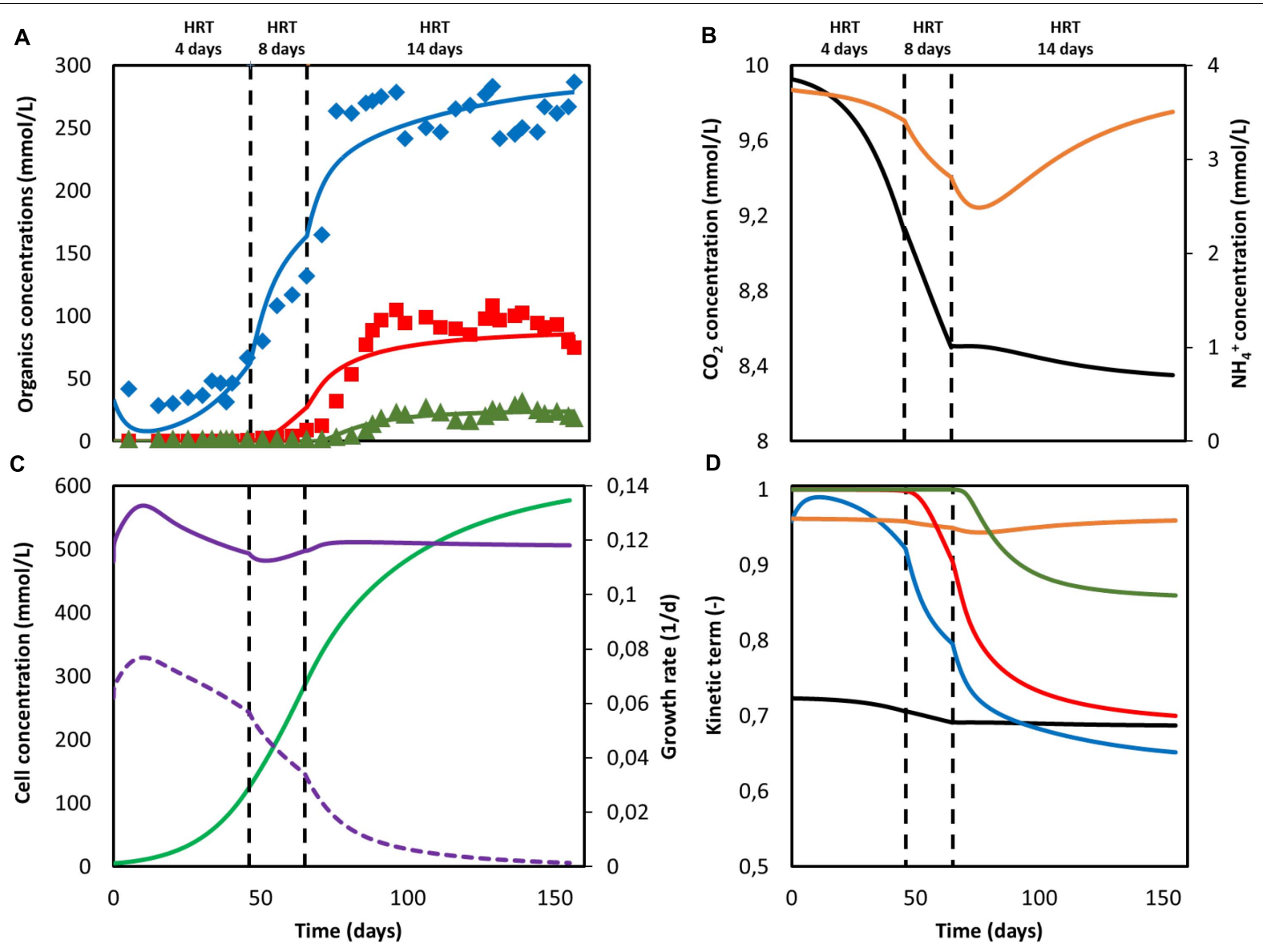

FIGURE 2 | Model fitting results (lines) and experimental data Jourdin et al. (2019) (markers). (A) Concentration of acetate (blue), butyrate (red) and caproate (green); (B) Substrate concentration of $\mathrm{CO}_{2}$ (black) and $\mathrm{NH}_{4}{ }^{+}$(orange); (C) Cell concentration (light green), maximum growth rate (purple), and growth rate (purple dashed line); (D) Kinetic uptake terms of $\mathrm{CO}_{2}$ (black) and $\mathrm{NH}_{4}{ }^{+}$(orange), and kinetic product inhibition terms of acetate (blue), butyrate (red), and caproate (dark green). The vertical dashed lines represent the time when the hydraulic retention time was increased.

gas-liquid mass transfer is sufficient to supply $\mathrm{CO}_{2}$ faster than what the microorganisms consume. Then, the uptake rate starts limiting the system. After an initial growth phase, all rates sharply decrease. This effect is induced by the increasing carboxylates concentrations and the subsequent product inhibition on cell metabolism (Supplementary Figures 2A-C in the Supplementary Information 2.2). The $\mathrm{CO}_{2}$ partial pressure $\left(\mathrm{p}_{\mathrm{CO}_{2}}\right)$ of the feed gas determines the saturation concentration at which carbon dioxide can be dissolved into the liquid (Weiss, 1974). Increasing this partial pressure substantially improves biomass production rate, as shown in Figure 3B. In this case, the positive effect is because of a higher driving force for gas-liquid mass transfer, i.e., the equilibrium concentration of $\mathrm{CO}_{2}$ with a $\mathrm{PCO}_{2}$ of 1 is of $34 \mathrm{mmol} / \mathrm{L}$, three times higher than with a partial pressure of 0.3 . The higher the partial pressure of $\mathrm{CO}_{2}$ used the more pronounced the effect of product inhibition is. This can be attributed to the microbial dynamics during the initial part of the run, reaching the carboxylates' inhibiting concentrations at a faster rate with higher $\mathrm{CO}_{2}$ fraction in the inlet gas (Supplementary Figures 2D-E in the Supplementary Information 2.2) (Figure 3).

\section{Model Validation: Prediction vs. Experimentation}

A wide range of biological systems and operational conditions applied to MES are described in literature. In this paper, and in order to study the prediction capabilities of the model, the work of Jourdin et al. (2018) and Marshall et al. (2013) were chosen because of their detailed experimental descriptions and model input parameters availability. The model structure is largely the same as in the fitting case previously discussed. Any model parameters modification done to reflect differences between the studied systems can be found in the Supplementary Informations 2.3, 2.4.

\section{$\mathrm{CO}_{2}$ Supply Strategy Greatly Impacts Reactor Performance}

Simulation results for the system utilized by Jourdin et al. (2018) can be found in Figure 4. The reactor was operated in fed-batch mode under a discontinuous $\mathrm{CO}_{2}$ sparging regime during periods I and III, in batch mode with continuous sparging of $\mathrm{CO}_{2}$ during period II and in continuous mode with 


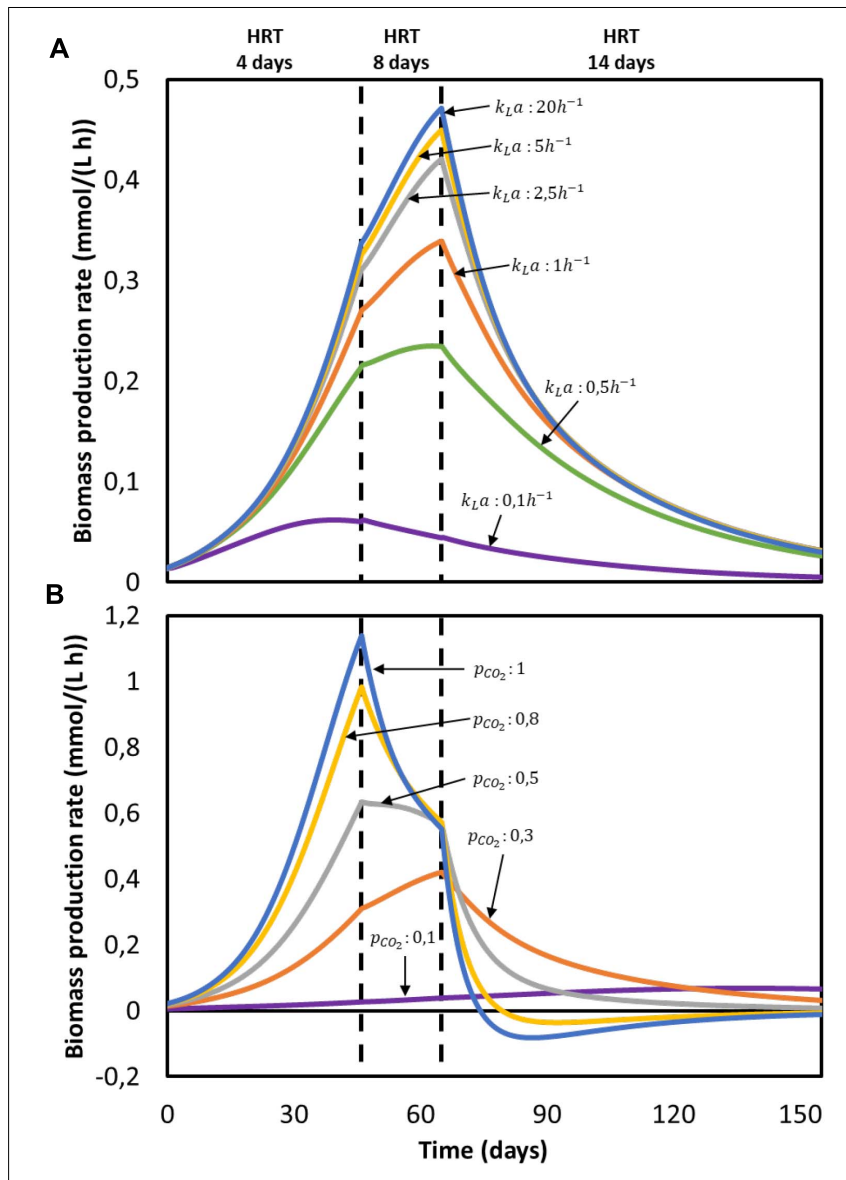

FIGURE 3 | Computed biomass production rate in time for the reactor from Jourdin et al. (2019): (A) at different gas-liquid mass transfer coefficients $\left(k_{L} a\right)$ with $p_{\mathrm{CO}_{2}}=0.3$ and $(\mathbf{B})$ at different gas $\mathrm{CO}_{2}$ partial pressures $\left(p_{\mathrm{CO}_{2}}\right)$ with $k_{L} a=2.5 h^{-1}$. No experimental data available.

continuous sparging of $\mathrm{CO}_{2}$ during period IV. When comparing the organics concentration obtained from the simulation with the experimental data, although showing a similar trend, the model predictions deviate from the experimental results (Figure 4A). Calculated acetate and n-butyrate concentrations are substantially higher, especially during periods II and III. For the data points, the population standard deviation of the model was $50.11 \mathrm{mmol} / \mathrm{L}$ for acetate, $10.79 \mathrm{mmol} / \mathrm{L}$ for butyrate, and $1.13 \mathrm{mmol} / \mathrm{L}$ for caproate.

This overshooting contrasts with the good description by the model of the current consumption, as can be seen in Figure 4E. This good match between simulation and experimental data on the electron consumption, together with the mismatch on organics prediction indicates an overestimation of the coulombic efficiency. These differences could be attributed to hydrogen production, as Jourdin et al. (2018) reported electron recoveries that ranged from $20 \%$ to $70 \%$ during the first three periods of the run and from $60 \%$ to $100 \%$ during the last period. This dynamic behavior between carboxylates production and hydrogen evolution is not included in the present model. During the fitting in section "Model Fitting", the biological rates from the model were calculated to match the organics concentration evolution over time from the experimental results. As a consequence, the coulombic efficiency of the system leading to electron losses was not taken into account. When the experimentally reported recoveries are applied to the organics concentration predicted by the model, a better representation of the experimental data is obtained (dashed lines in Figure 4A). The population standard deviation of the adjusted model was $32.09 \mathrm{mmol} / \mathrm{L}$ for acetate, $3.62 \mathrm{mmol} / \mathrm{L}$ for butyrate, and $0.68 \mathrm{mmol} / \mathrm{L}$ for caproate. This highlights that the model presented in this paper is able to predict the performance of a MES system with a $100 \%$ coulombic efficiency, giving for a certain set of conditions an approximation of what the best possible outcome can be (Figure 4).

As can be seen in Figure 4B, carbon dioxide was periodically depleted in periods I and III as the multiple sparging periods were not able to keep up with its consumption rate. When the feeding strategy was changed to continuous addition in period II, an initial decrease with a later slight increase of $\mathrm{CO}_{2}$ concentration is observed, but no depletion occurred. The later increase of the $\mathrm{CO}_{2}$ concentration can be attributed to the plateauing of the biomass concentration (see Figure 4C; Hwang et al., 2020), as the model shows that the ammonium concentration was continuously decreasing and close to being depleted. No nitrogen limitation was observed. Ammonium concentration slightly decreased but stayed high during period I, severely decreased in period II and increased during period III. This later increase can be attributed to the carbon dioxide depletion and the subsequent halt of cell growth, inducing cell death and a decrease of the biomass concentration (Figure 4C; Váchová and Palková, 2005). During period IV, when the operational mode was switched from batch to continuous, i.e., nutrients and $\mathrm{CO}_{2}$ were continuously added, $\mathrm{CO}_{2}$ concentration shows an initial decrease with a later stabilization when the steady-state is reached. On the other hand, $\mathrm{NH}_{4}{ }^{+}$concentration peaks at the beginning and then slowly stabilizes. This sharp increase is attributed to the accumulation produced by the constantly added fresh medium.

The depletion of carbon dioxide during fed-batch periods completely stopped the growth metabolism of the cells (Figure 4D). Even though the nitrogen source could be expected to become the bottleneck of the system during period II, the uptake of $\mathrm{CO}_{2}$ was still the rate limiting microbial kinetics. This can be attributed to the low ammonium half-saturation constant, buffering the effect of a low concentration on the overall kinetics. Again, when the operational mode was switched to continuous in period IV and the steady-state was reached, the $\mathrm{CO}_{2}$ uptake term was the limiting factor, decreasing the maximum rate by about $65 \%$. In summary, it is clear that the limiting step during the entire duration of Jourdin's experiment was the supply of carbon dioxide, pointing out to the importance of not only the amount of $\mathrm{CO}_{2}$ added but also how this addition is carried out.

\section{Continuous Operation Benefits Biofilm Growth}

A second simulation to reproduce the set of data obtained by Marshall et al. (2013) was performed, and the results obtained from the model are showed in Figure 5. A series of consecutive batches was simulated. After every batch, the catholyte was 
A
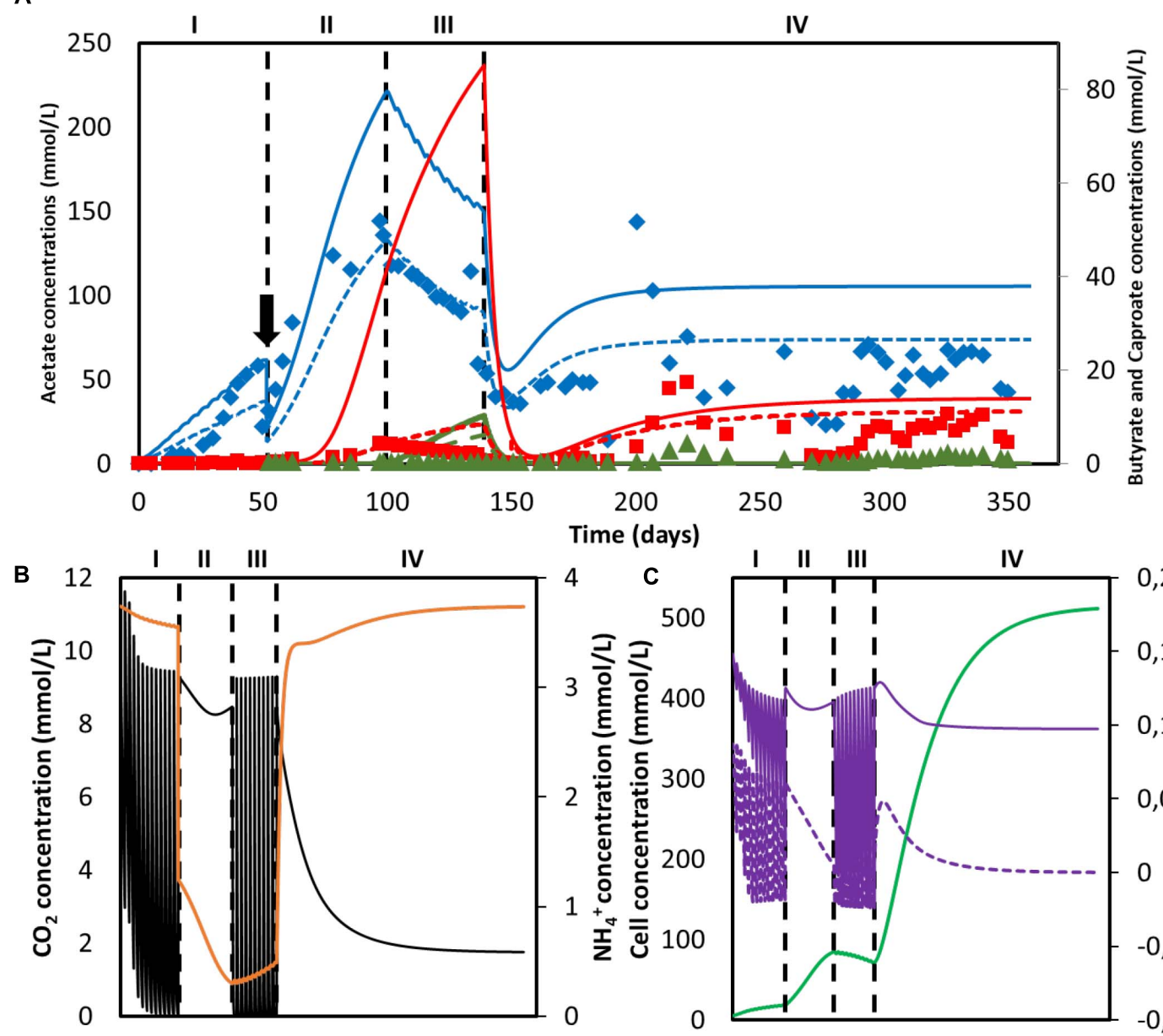

Time (days)

4 C

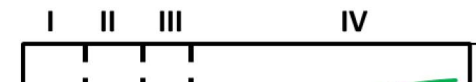

0,2
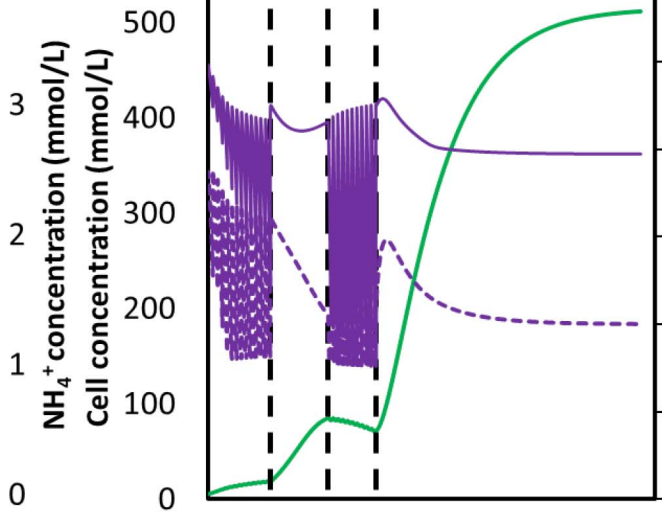

0,15
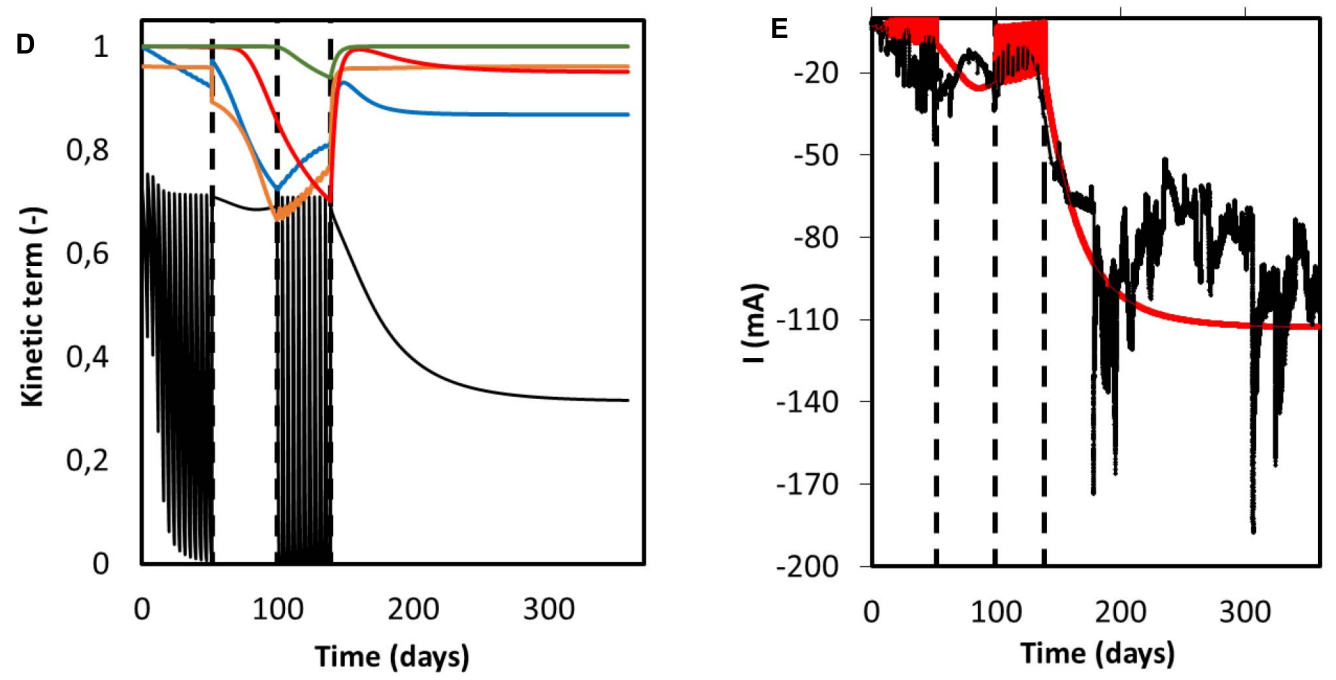

FIGURE 4 | Simulation results of a MES system with changing feed strategies and operational modes. (A) Predicted concentration of acetate (solid blue line), n-butyrate (solid red line) and n-caproate (solid dark green line) and experimental data from Jourdin et al. (2018) of acetate (blue diamonds), n-butyrate (red squares), and $\mathrm{n}$-caproate (dark green triangles). Adjusted concentrations with reported electron recoveries are shown with dashed lines for acetate (blue), $\mathrm{n}$-butyrate (red), and n-caproate (dark green); (B) Concentration of $\mathrm{CO}_{2}$ (black) and $\mathrm{NH}_{4}+$ (orange); (C) Microbial cell concentration (light green), calculated maximum growth rate (purple), and growth rate (purple dashed line); (D) Kinetic hyperbolic uptake terms of $\mathrm{CO}_{2}$ (black) and $\mathrm{NH}_{4}^{+}$(orange), and kinetic product inhibition terms of acetate (blue), n-butyrate (red), and n-caproate (dark green); (E) Predicted (red) and experimental (black) current. The vertical dashed lines represent the time when reactor operation was switched from fed-batch to batch and from batch to continuous mode. The black arrow indicates when substantial leakage of the medium occurred. 
A

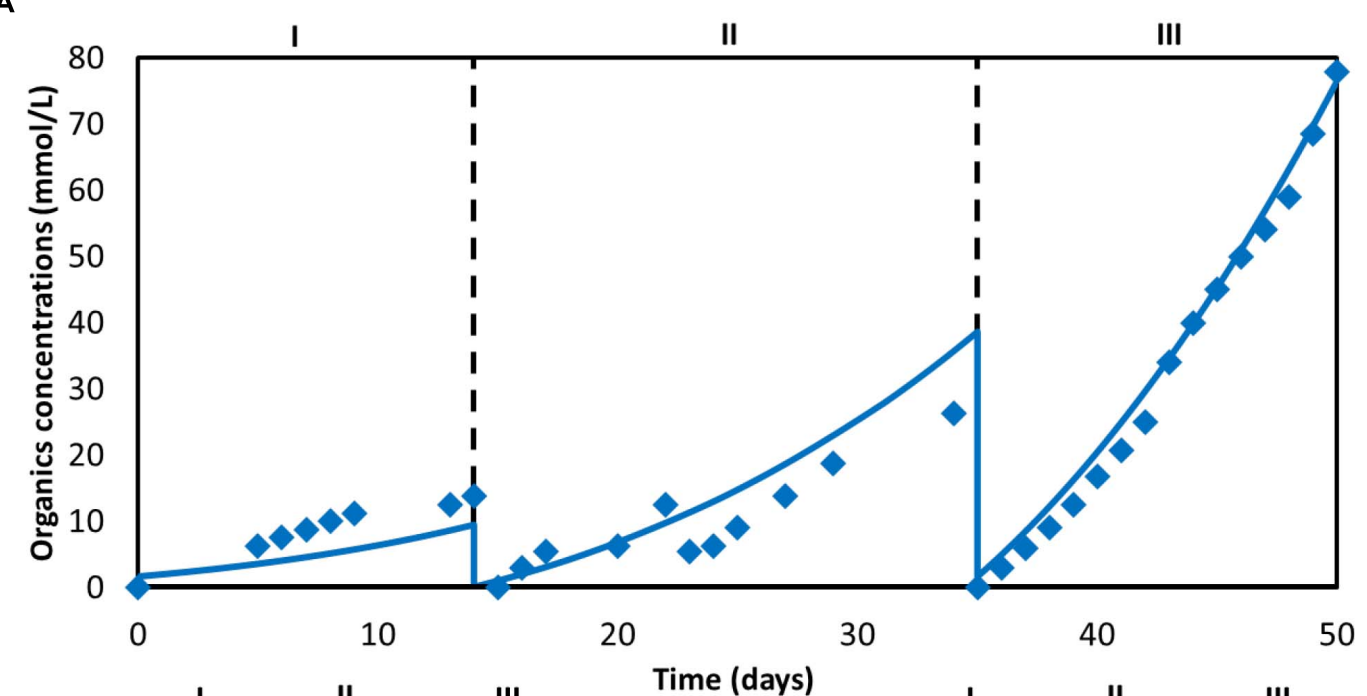

B

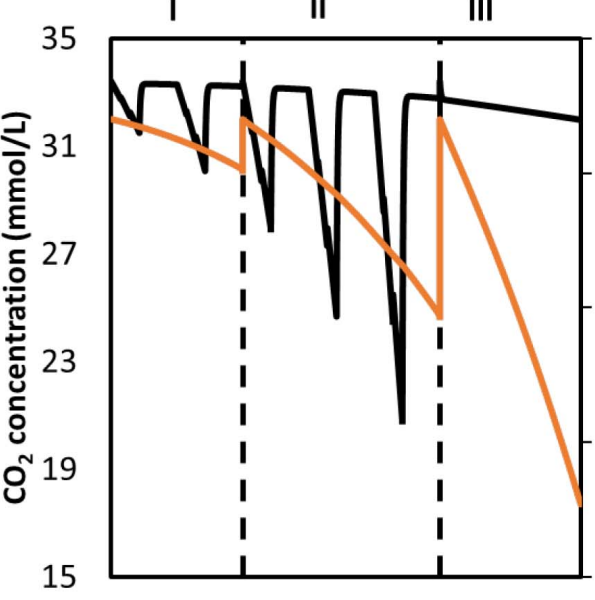

Time (days)

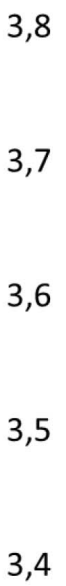

c 30

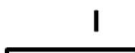

II III 
replaced by fresh medium while the biomass remained attached to the electrode material. The first two batches (periods I and II) operated under a discontinuous $\mathrm{CO}_{2}$ sparging regime, whereas the third batch (period III) was continuously sparged with pure $\mathrm{CO}_{2}$. The model properly predicts the acetate concentration profile obtained experimentally (Figure 5A). For the data points, the population standard deviation of the model was $1.94 \mathrm{mmol} / \mathrm{L}$ for acetate. The elongation thresholds from Eq. 15 and Eq. 16 allowed to properly reproduce a system where only acetate was produced (Figure 5).

Carbon dioxide concentration oscillated during the intermittent sparging phases in periods I and II and showed a subtle decrease during period III, but was far from being depleted (Figure 5B). However, it should be stressed that the actual $k_{L} a$ of their sparging method was not reported and thus assumed to be the same as in Jourdin et al. (2019). Therefore it is difficult to conclude the system was not $\mathrm{CO}_{2}$ limited. $\mathrm{NH}_{4}{ }^{+}$ concentration showed a batch-like behavior, decreasing faster in every consecutive batch. This is attributed to the increasing biomass concentration and its exponential behavior, as according to the model nitrogen consumption is strictly bounded to microbial growth (Figure 5C). Although nitrogen uptake rate was exponentially increasing, $\mathrm{NH}_{4}{ }^{+}$was far from depletion.

The biomass concentration obtained after 50 days ( $25 \mathrm{mmol} / \mathrm{L}$ ) is five times lower than the amount produced in a continuous reactor with constant $\mathrm{CO}_{2}$ sparging $(125 \mathrm{mmol} / \mathrm{L})$, as can be seen when comparing Figures 2C, 5C. The effect of the dilution rate on the biomass growth is shown in Figure 6. The higher biomass concentration achieved with biofilm-driven systems operating in continuous mode can be attributed to the exchange flow. Since microorganisms grow attached to the electrode, and are therefore not affected by this dilution rate, the difference in growth rate is caused by the other dilute species concentrations in the system. In continuous operation, nutrients are constantly replenished while products are removed from the reactor, diminishing the effects of low substrate concentrations and product inhibition (Michel-Savin et al., 1990; Andrić et al., 2010). However, in a batch system like the one used by Marshall et al. (2013), nutrients deplete and products accumulate faster over time.

The kinetic parameters are presented in Figure 5D. Carbon dioxide uptake was the limiting kinetic rate during all three batches. During the last intermittent sparging phase in period II a total decrease of the maximum uptake rate up to $15 \%$ was reached, but stabilized at $10 \%$ in period III when continuous gas sparging was applied. Although a $30 \%$ decrease on the carbon concentration during period II is observed in Figure 5B, the use of pure $\mathrm{CO}_{2}$ by Marshall helped to mitigate the effect on the microbial kinetics. The amount of carbon dioxide that can be dissolved in the system increases linearly with the $\mathrm{CO}_{2}$ partial pressure used in the gas (Weiss, 1974). A 3.3 times higher $\mathrm{CO}_{2}$ liquid concentration was obtained by the use of $100 \% \mathrm{CO}_{2}$ as feeding gas when compared with the $30 \%$ used by Jourdin et al. (2018). This higher concentration mitigated the decrease of the hyperbolic term for $\mathrm{CO}_{2}$ uptake and avoided a more severe rate inhibition by the carbon source. Since the limiting effect of $\mathrm{CO}_{2}$ and other chemical species in microbial kinetics is low, it is

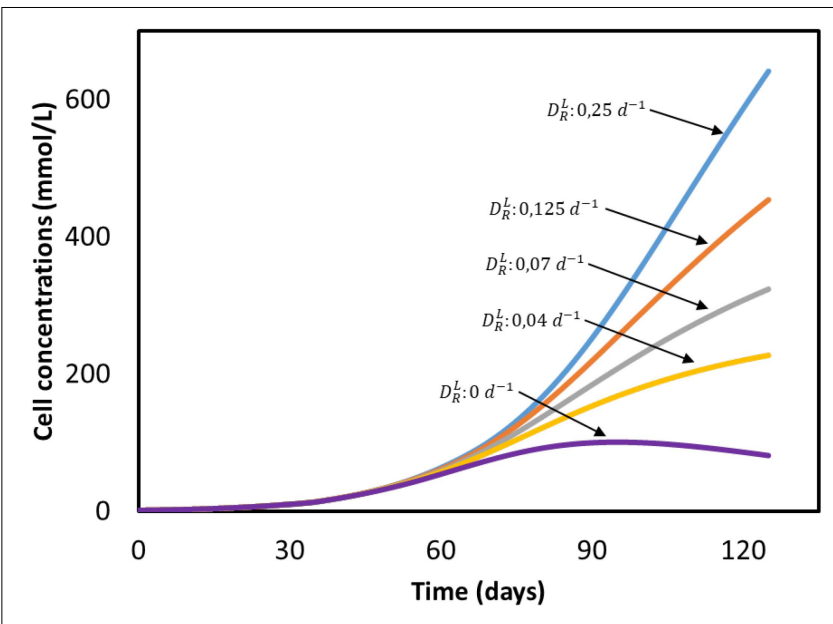

FIGURE 6 | Cell concentrations in time at different dilution rates $\left(D_{R}^{L}\right)$ based on the system from Marshall et al. (2013). All input parameters are the same between simulations, with the exception of the dilution rate. No experimental data available.

likely that the reactor was limited by the absolute amount of biomass in the system.

The current in periods II and III is correctly described by the model, as can be seen in Figure 5E. However, during the first period, predictions substantially deviate from the experimental values, with the calculated ones being lower than the ones observed by Marshall. Again, this deviation can be attributed to hydrogen and other by-products formation, as side-reactions are not accounted for in the current model. Microbial attachment and biofilm formation can be a slow process in MES systems, as bacteria do not obtain much energy from $\mathrm{CO}_{2}$ reduction (Schuchmann and Müller, 2014). Hence, it is likely the case that during the first batch, as the biomass was starting to colonize the cathode, electrons were redirected toward hydrogen evolution. When cell concentration further increased, these electrons started being used in microbial reactions instead, giving the initial increase in the cathodic current observed at the beginning of period II (Figure 6).

\section{Model Assumptions Evaluation Concentration Gradients Over the Reactor}

The model assumes no concentration gradients in the individual domains. Hence, concentration steps occur only between the domains or at the inflow. To support the assumption that gradients are negligible, the magnitude of the concentration steps will be discussed. Experimental measurements were performed at the sampling port ( $S$ in Figure 1B), thus computed concentrations refer to those leaving the second bulk liquid compartment $\left(C_{i}^{B 2}\right)$. Individual mass balances over each domain, together with an explanation on how the concentration gradients were calculated can be found in the Supplementary Information 3.1. Taking into consideration all compounds present in the system, carbon dioxide and protons are the ones expected to have the highest concentration steps along the reactor. 


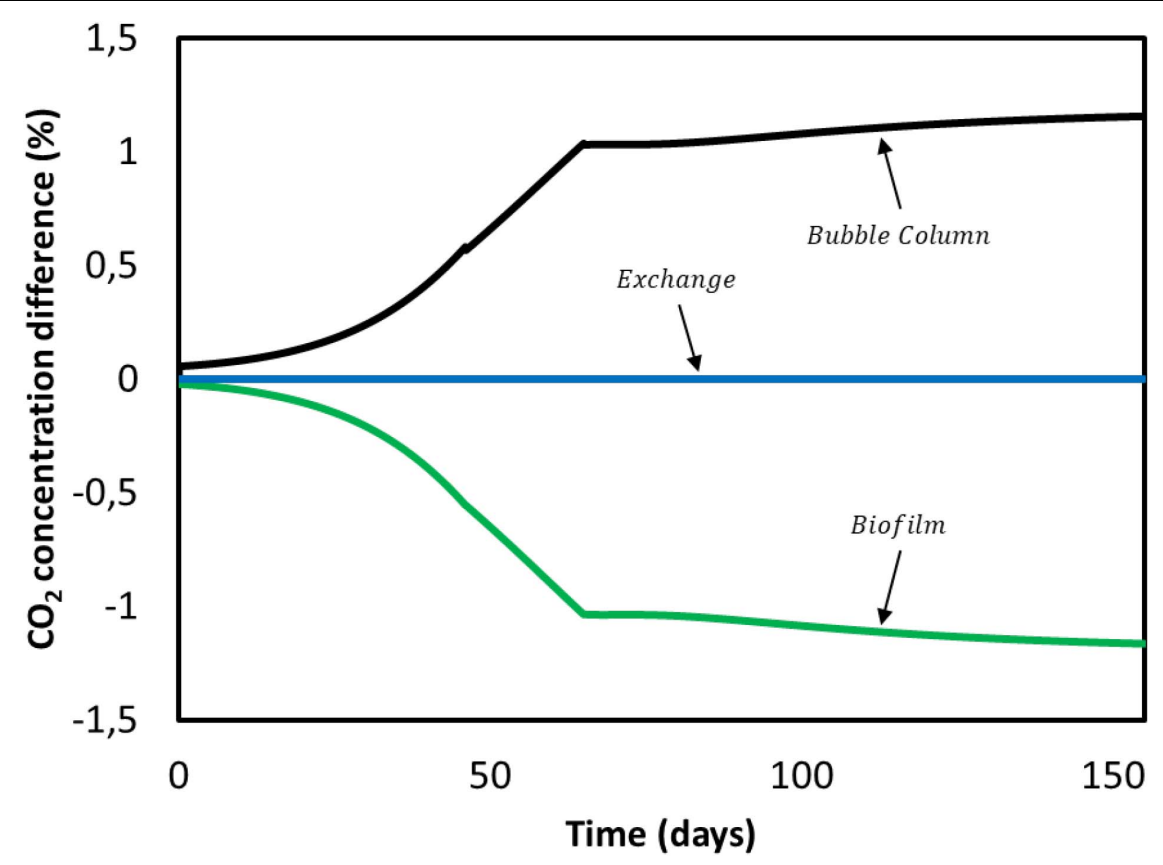

FIGURE $7 \mid \mathrm{CO}_{2}$ concentration difference between domains during Jourdin et al. (2019) experiment.

First, we focus on carbon dioxide. It is consumed by the microorganisms in the biofilm domain and transfers from the gas phase to the bulk liquid in the bubble column. Results obtained for $\mathrm{CO}_{2}$ concentration gradients over the entire duration of Jourdin et al. (2019) experiment are shown in Figure 7. Positive values indicate a concentration increase between the previous and the current compartment, whereas a negative value refers to consumption. In no case the concentration difference exceeds $\pm 1.5 \%$. This is attributed to the small ratio between the dilution flow rate of $0.018 \mathrm{~mL} / \mathrm{min}$ and the recirculation rate of $200 \mathrm{~mL} / \mathrm{min}$. The characteristic $\mathrm{CO}_{2}$ reaction time is estimated to be $4 \mathrm{~min}$, while the residence time of the convective flow is $0.13 \mathrm{~min}$ (Supplementary Information 3.2). The ratio between these times causes overall concentration changes in the system to become significant after multiple recirculations rather than after a single pass through the biofilm domain. Therefore, for the purpose of this model $\mathrm{CO}_{2}$ concentration gradients in the reactor domains can be neglected (Figure 7).

\section{$\mathrm{pH}$ at the Biofilm}

The $\mathrm{pH}$ of a biologically active cathodic chamber is highly dependent on the acid-base reaction equilibria. $\mathrm{CO}_{2}$ and all products accounted for in the current model behave as acid. In addition, the presence of a buffer must also be taken into consideration. It is therefore the balance between these production and consumption processes, that determines local $\mathrm{pH}$ gradients. In the present study, $\mathrm{pH}$ was assumed to be constant but since it has a great influence on both electrochemical and biological reactions, this assumption needs to be further investigated.
Bulk pH is strictly monitored and controlled by acid and base addition, therefore gradients due to protons diffusing from anode to biofilm can be neglected. However, reactions are happening within the biofilm and not in the liquid bulk, therefore a gradient might still be present at the vicinity of the electrode. An estimation of both characteristic reaction and diffusion times for $\mathrm{CO}_{2}, \mathrm{H}^{+}$, and the buffer compound was used to determine if large $\mathrm{pH}$ gradients would be present in the biofilm. These calculations and respective explanations can be found in the Supplementary Information 3.2. Results indicate that although $\mathrm{H}^{+}$ions are not able to diffuse into the biofilm quick enough, the presence of a buffer allows to compensate for the consumed $\mathrm{H}^{+}$in the biofilm by a buffering reaction with a reaction time in the same order of magnitude as for $\mathrm{CO}_{2}$. According to the calculated diffusion and reaction times, $\mathrm{CO}_{2}$ diffusion slowed down the biological reaction, which at the same time limited the proton consumption rate by the microorganism. The protonated buffer compound diffusion through the biofilm and buffering reaction would then have to keep up to effectively control $\mathrm{pH}$. By analogy to the case treated by Vander Wielen et al. (1997), the mentioned decrease in the general metabolic rate may have been sufficient to allow the buffer to prevent large $\mathrm{pH}$ gradients. A real biofilm is not homogeneous, and large gradients might occur at conditions different from those simulated here. Experimental data on $\mathrm{pH}$ values throughout the biofilm are required to validate the calculations.

\section{Potential Model Improvements}

Only one bacterial population has been included in this model, even though the simulated reactors were systems working with mixed cultures. Therefore, the model could 
be expanded to include multiple microorganisms with differentiated metabolisms (Rauch et al., 1999; Xavier et al., 2005). As an example, solventogenesis (i.e., ethanol production from acetate) and chain elongation could be described independently from acetogenesis, allowing a deeper investigation of possible interactions between intermediate compounds, substrates, and microorganisms. It could also lead to a better understanding of which metabolic routes are being used by microorganisms to reduce $\mathrm{CO}_{2}$ into longer chain products such as caproate.

As previously described, $\mathrm{pH}$ gradients and other chemicals' gradients should be further investigated for biofilm-driven systems. The addition of acid-base equilibria, hydrogen evolution, and electromigration would allow to better understand gradients at the biofilm level, potentially giving additional insights on rate limiting processes. These gradients could also help to understand biofilm development and biofilm/planktonic cells dynamics. Moreover, mass and ion transport can be expected to become of paramount importance as MES current density and microbial productivity continue to increase (Jourdin and Burdyny, 2020). In this sense, extending the model to a multi-dimensional model such as the ones developed in Picioreanu et al. (2007), Picioreanu et al. (2010), Bottero et al. (2013) for microbial fuel cells could be interesting for this purpose.

The use of a product inhibition model is necessary to account for the inherent toxicity of the produced carboxylates. Even though the model used in this paper gave good results, it should be expanded and validated with experiments in which products have been added to the inflow. This would give a better and more tailored description of product toxicity within these systems, and subsequently a better understanding of chain elongation metabolism and kinetics.

\section{Model Implications}

Simulations done in this work suggest that $\mathrm{CO}_{2}$ can limit the rate of microbial electrosynthesis. Carbon dioxide is the main substrate and the only carbon source in most MES reactors, hence its concentration has a great impact on cell kinetics. Its relatively high half-saturation constant and low solubility make microorganisms very susceptible to small changes in its dissolved concentration. The model indicates that the use of pure $\mathrm{CO}_{2}$ as feeding gas can mitigate this effect, as shown experimentally in Rojas et al. (2021). However, it is important to note here that avoiding a kinetic limitation may not be enough to substantially increase productivity, since $\mathrm{CO}_{2}$ diffusion might become the limiting step at some point. Results also indicate not to underestimate the critical effect of the $\mathrm{CO}_{2}$ delivery strategy on reactor performance (Izadi et al., 2020). In MES studies, mass transfer coefficients are hardly ever reported, therefore it is difficult to conclude that poor $\mathrm{CO}_{2}$ delivery systems are one of the reasons why obtained production rates are still low across the field (Prévoteau et al., 2020). Regardless of the supply method used, its mass transfer capability should always be assessed. The model developed in this work can be used to determine the minimum mass transfer capability required to avoid kinetic limitations by the supply method. By ensuring that the used system is able to deliver enough $\mathrm{CO}_{2}$ to sustain a highly active microbial population, a better understanding can be achieved of which steps are intrinsically limiting steps in said MES processes.

To date, most MES studies have been performed under batch conditions and not many researchers used a continuous reactor for reducing $\mathrm{CO}_{2}$ (Batlle-Vilanova et al., 2016; Arends et al., 2017; Bajracharya et al., 2017; LaBelle and May, 2017; Molenaar et al., 2017; Jourdin and Burdyny, 2020). The model indicates that the continuous mode enhances cell growth, hence it might be one of the reasons why dense biofilms have been mainly obtained with this type of reactors. This can be attributed to a selective pressure that benefits attached cells since under a continuous operation, planktonic populations are easily washed out the reactor. However, biofilm development is subject to multiple parameters, and the operational mode is just one of them. It has to be noted that increasing the capacity for growth of a bacterial population does not necessarily mean that the culture will be able to grow that much. As an example, in biofilm-driven systems the electrode surface area available for attachment and its roughness are also key parameters that limit the development of a thick biofilm (Myint et al., 2010; Ammar et al., 2015). In that sense, the model can be used to calculate the maximum cell growth that can be obtained with a certain system under a specific set of operational conditions.

\section{CONCLUSION}

The mathematical model presented in this work is able to accurately describe the behavior of different biofilmdriven MES reactors operating in batch, fed-batch, and continuous mode. It was found that under previously reported operational conditions biomass growth was partially limited by the $\mathrm{CO}_{2}$ dissolved concentration. This implies that a more careful assessment of the inorganic carbon supply method is needed to increase production rates. Furthermore, simulations show that operating in continuous mode leads to higher cell densities. Since most current studies are done in batch mode, this might be one of the reasons why cell titers are far below their theoretical maximum (Jourdin and Burdyny, 2020; Prévoteau et al., 2020). These results demonstrate the value of such models in understanding MES systems, and highlight their usefulness when analyzing current process limitations.

\section{DATA AVAILABILITY STATEMENT}

The original contributions presented in the study are included in the article/Supplementary Material, further inquiries can be directed to the corresponding author/s.

\section{AUTHOR CONTRIBUTIONS}

OC-P developed the model and drafted the manuscript. AS and LJ contributed to the modeling effort and 
data interpretation. All authors contributed to manuscript revision, conception, design of the study, read and approved the submitted version.

\section{FUNDING}

This activity is co-financed by Shell and a PPP-allowance from Top Consortia for Knowledge and Innovation (TKI's) of the

\section{REFERENCES}

Abel, A. J., and Clark, D. S. (2020). A comprehensive modeling analysis of formate-mediated microbial electrosynthesis. ChemSusChem 14, 344-355. doi: $10.1002 /$ cssc. 202002079

Ahring, B. K., and Westermann, P. (1987). Kinetics of butyrate, acetate, and hydrogen metabolism in a thermophilic, anaerobic, butyrate-degrading triculture. Appl. Environ. Microbiol. 53, 434-439. doi: 10.1128/aem.53.2.434439.1987

Alqahtani, M. F., Katuri, K. P., Bajracharya, S., Yu, Y., Lai, Z., and Saikaly, P. E. (2018). Porous hollow fiber nickel electrodes for effective supply and reduction of carbon dioxide to methane through microbial electrosynthesis. Adv. Funct. Mater. 28:1804860. doi: 10.1002/adfm.201804860

Ammar, Y., Swailes, D., Bridgens, B., and Chen, J. (2015). Influence of surface roughness on the initial formation of biofilm. Surf. Coat. Technol. 284, 410-416. doi: 10.1016/j.surfcoat.2015.07.062

Andrić, P., Meyer, A. S., Jensen, P. A., and Dam-Johansen, K. (2010). Reactor design for minimizing product inhibition during enzymatic lignocellulose hydrolysis: II. Quantification of inhibition and suitability of membrane reactors. Biotechnol. Adv. 28, 407-425. doi: 10.1016/j.biotechadv.2010. 02.005

Arends, J. B., Patil, S. A., Roume, H., and Rabaey, K. (2017). Continuous longterm electricity-driven bioproduction of carboxylates and isopropanol from CO2 with a mixed microbial community. J. CO2 Util. 20, 141-149. doi: 10. 1016/j.jcou.2017.04.014

Bader, F. (1978). Analysis of double-substrate limited growth. Biotechnol. Bioeng. 20, 183-202. doi: 10.1002/bit.260200203

Bae, W., and Rittmann, B. E. (1996). A structured model of dual-limitation kinetics. Biotechnol. Bioeng. 49, 683-689. doi: 10.1002/(sici)10970290(19960320)49:6<683::aid-bit10>3.0.co;2-7

Bajracharya, S., Vanbroekhoven, K., Buisman, C. J., Pant, D., and Strik, D. P. (2016). Application of gas diffusion biocathode in microbial electrosynthesis from carbon dioxide. Environ. Sci. Pollut. Res. 23, 22292-22308. doi: 10.1007/ s11356-016-7196-x

Bajracharya, S., Vanbroekhoven, K., Buisman, C. J., Strik, D. P., and Pant, D. (2017). Bioelectrochemical conversion of $\mathrm{CO} 2$ to chemicals: $\mathrm{CO} 2$ as a next generation feedstock for electricity-driven bioproduction in batch and continuous modes. Faraday Discuss. 202, 433-449. doi: 10.1039/c7fd00050b

Batlle-Vilanova, P., Ganigué, R., Ramió-Pujol, S., Bañeras, L., Jiménez, G., Hidalgo, M., et al. (2017). Microbial electrosynthesis of butyrate from carbon dioxide: production and extraction. Bioelectrochemistry 117, 57-64. doi: 10.1016/j. bioelechem.2017.06.004

Batlle-Vilanova, P., Puig, S., Gonzalez-Olmos, R., Balaguer, M. D., and Colprim, J. (2016). Continuous acetate production through microbial electrosynthesis from CO2 with microbial mixed culture. J. Chem. Technol. Biotechnol. 91, 921-927. doi: $10.1002 /$ jctb.4657

Battley, E. H. (1987). Energetics of Microbial Growth. New York, NY: Wiley.

Blanchet, E., Duquenne, F., Rafrafi, Y., Etcheverry, L., Erable, B., and Bergel, A. (2015). Importance of the hydrogen route in up-scaling electrosynthesis for microbial CO 2 reduction. Energy Environ. Sci. 8, 3731-3744. doi: 10.1039/ c5ee03088a

Bottero, S., Storck, T., Heimovaara, T. J., van Loosdrecht, M. C. M., Enzien, M. V., and Picioreanu, C. (2013). Biofilm development and the dynamics of preferential flow paths in porous media. Biofouling 29, 1069-1086. doi: 10. $1080 / 08927014.2013 .828284$
Dutch Ministry of Economic Affairs and Climate in the context of the TU Delft e-Refinery Institute.

\section{SUPPLEMENTARY MATERIAL}

The Supplementary Material for this article can be found online at: https://www.frontiersin.org/articles/10.3389/fmicb. 2021.669218/full\#supplementary-material

Chen, Y., and Hashimoto, A. (1980). Substrate utilization kinetic model for biological treatment process. Biotechnol. Bioeng. 22, 2081-2095. doi: 10.1002/ bit.260221008

Dubouchaud, H., Walter, L., Rigoulet, M., and Batandier, C. (2018). Mitochondrial $\mathrm{NADH}$ redox potential impacts the reactive oxygen species production of reverse electron transfer through complex I. J. Bioenerg. Biomembr. 50, 367377. doi: 10.1007/s10863-018-9767-7

Enzmann, F., Mayer, F., Stöckl, M., Mangold, K.-M., Hommel, R., and Holtmann, D. (2019). Transferring bioelectrochemical processes from $\mathrm{H}$-cells to a scalable bubble column reactor. Chem. Eng. Sci. 193, 133-143. doi: 10.1016/j.ces.2018. 08.056

Flexer, V., and Jourdin, L. (2020). Purposely designed hierarchical porous electrodes for high rate microbial electrosynthesis of acetate from carbon dioxide. Acc. Chem. Res. 53, 311-321. doi: 10.1021/acs.accounts.9b00523

Gadkari, S., Shemfe, M., Modestra, J. A., Mohan, S. V., and Sadhukhan, J. (2019). Understanding the interdependence of operating parameters in microbial electrosynthesis: a numerical investigation. Phys. Chem. Chem. Phys. 21, 1076110772. doi: 10.1039/c9cp01288e

Ganigué, R., Puig, S., Batlle-Vilanova, P., Balaguer, M. D., and Colprim, J. (2015). Microbial electrosynthesis of butyrate from carbon dioxide. Chem. Commun. 51, 3235-3238. doi: 10.1039/c4cc10121a

Ghose, T., and Tyagi, R. (1979). Rapid ethanol fermentation of cellulose hydrolysate. II. Product and substrate inhibition and optimization of fermentor design. Biotechnol. Bioeng. 21, 1401-1420. doi: 10.1002/bit.260210808

Giddings, C. G., Nevin, K. P., Woodward, T., Lovley, D. R., and Butler, C. S. (2015). Simplifying microbial electrosynthesis reactor design. Front. Microbiol. 6:468. doi: 10.3389/fmicb.2015.00468

Hamelers, H. V., Ter Heijne, A., Stein, N., Rozendal, R. A., and Buisman, C. J. (2011). Butler-Volmer-Monod model for describing bio-anode polarization curves. Bioresour. Technol. 102, 381-387. doi: 10.1016/j.biortech.2010.06.156

Heijnen, J., and Van Dijken, J. (1992). In search of a thermodynamic description of biomass yields for the chemotrophic growth of microorganisms. Biotechnol. Bioeng. 39, 833-858. doi: 10.1002/bit.260390806

Hwang, J., Hari, A., Cheng, R., Gardner, J. G., and Lobo, D. (2020). Kinetic modeling of microbial growth, enzyme activity, and gene deletions: an integrated model of $\beta$-glucosidase function in Cellvibrio japonicus. Biotechnol. Bioeng. 117, 3876-3890. doi: 10.1002/bit.27544

Izadi, P., Fontmorin, J.-M., Godain, A., Eileen, H. Y., and Head, I. M. (2020). Parameters influencing the development of highly conductive and efficient biofilm during microbial electrosynthesis: the importance of applied potential and inorganic carbon source. NPJ Biofilms Microbiomes 6, 1-15.

Jourdin, L., and Burdyny, T. (2020). Microbial electrosynthesis: where do we go from here? Trends Biotechnol. 39, 359-369. doi: 10.1016/j.tibtech.2020.10.014

Jourdin, L., Lu, Y., Flexer, V., Keller, J., and Freguia, S. (2016). Biologically induced hydrogen production drives high rate/high efficiency microbial electrosynthesis of acetate from carbon dioxide. ChemElectroChem 3, 581-591. doi: 10.1002/ celc. 201500530

Jourdin, L., Raes, S. M., Buisman, C. J., and Strik, D. P. (2018). Critical biofilm growth throughout unmodified carbon felts allows continuous bioelectrochemical chain elongation from $\mathrm{CO} 2$ up to caproate at high current density. Front. Energy Res. 6:7. doi: 10.3389/fenrg.2018.00007

Jourdin, L., Sousa, J., van Stralen, N., and Strik, D. P. (2020). Techno-economic assessment of microbial electrosynthesis from $\mathrm{CO} 2$ and/or organics: an interdisciplinary roadmap towards future research and application. Appl. Energy 279:115775. doi: 10.1016/j.apenergy.2020.115775 
Jourdin, L., and Strik, D. (2017). "Electrodes for cathodic microbial electrosynthesis processes: key-developments and criteria for effective research \& implementation," in Functional Electrodes for Enzymatic and Microbial Bioelectrochemical Systems, eds N. Brun and V. Flexer (Wageningen: World Scientific Publishing), 429-473. doi: 10.1142/9781786343543_0012

Jourdin, L., Winkelhorst, M., Rawls, B., Buisman, C. J. N., and Strik, D. P. B. T. B. (2019). Enhanced selectivity to butyrate and caproate above acetate in continuous bioelectrochemical chain elongation from $\mathrm{CO} 2$ : Steering with $\mathrm{CO} 2$ loading rate and hydraulic retention time. Bioresour. Technol. Rep. 7:100284. doi: 10.1016/j.biteb.2019.100284

Kazemi, M., Biria, D., and Rismani-Yazdi, H. (2015). Modelling bioelectrosynthesis in a reverse microbial fuel cell to produce acetate from $\mathrm{CO} 2$ and H 2 O. Phys. Chem. Chem. Phys. 17, 12561-12574. doi: 10.1039/c5cp00904a

Kerzenmacher, S. (2017). Engineering of microbial electrodes. Bioelectrosynthesis 167, 135-180. doi: 10.1007/10_2017_16

Kleerebezem, R., and Van Loosdrecht, M. C. (2010). A generalized method for thermodynamic state analysis of environmental systems. Crit. Rev. Environ. Sci. Technol. 40, 1-54. doi: 10.1080/10643380802000974

Klemps, R., Schoberth, S. M., and Sahm, H. (1987). Production of acetic acid by Acetogenium kivui. Appl. Microbiol. Biotechnol. 27, 229-234.

Korth, B., and Harnisch, F. (2017). Modeling microbial electrosynthesis. Bioelectrosynthesis 167, 273-325. doi: 10.1007/10_2017_35

Korth, B., Rosa, L. F., Harnisch, F., and Picioreanu, C. (2015). A framework for modeling electroactive microbial biofilms performing direct electron transfer. Bioelectrochemistry 106, 194-206. doi: 10.1016/j.bioelechem.2015.03.010

Kracke, F., and Krömer, J. O. (2014). Identifying target processes for microbial electrosynthesis by elementary mode analysis. BMC Bioinformatics 15:410. doi: 10.1186/s12859-014-0410-2

LaBelle, E. V., and May, H. D. (2017). Energy efficiency and productivity enhancement of microbial electrosynthesis of acetate. Front. Microbiol 8:756. doi: $10.3389 /$ fmicb.2017.00756

Lewis, N. S., and Nocera, D. G. (2006). Powering the planet: chemical challenges in solar energy utilization. Proc. Natl. Acad. Sci. 103, 15729-15735. doi: 10.1073/ pnas. 0603395103

Lovley, D. R., and Nevin, K. P. (2013). Electrobiocommodities: powering microbial production of fuels and commodity chemicals from carbon dioxide with electricity. Curr. Opin. Biotechnol. 24, 385-390. doi: 10.1016/j.copbio.2013.02. 012

Ly, H. K., Harnisch, F., Hong, S. F., Schröder, U., Hildebrandt, P., and Millo, D. (2013). Unraveling the interfacial electron transfer dynamics of electroactive microbial biofilms using surface-enhanced Raman spectroscopy. ChemSusChem 6, 487-492. doi: 10.1002/cssc.201200626

Marshall, C. W., Ross, D. E., Fichot, E. B., Norman, R. S., and May, H. D. (2013). Long-term operation of microbial electrosynthesis systems improves acetate production by autotrophic microbiomes. Environ. Sci. Technol. 47, 6023-6029. doi: $10.1021 /$ es400341b

Marshall, C. W., Ross, D. E., Handley, K. M., Weisenhorn, P. B., Edirisinghe, J. N., Henry, C. S., et al. (2017). Metabolic reconstruction and modeling microbial electrosynthesis. Sci. Rep. 7:8391.

Michel-Savin, D., Marchal, R., and Vandecasteele, J. (1990). Butyrate production in continuous culture of Clostridium tyrobutyricum: effect of end-product inhibition. Appl. Microbiol. Biotechnol. 33, 127-131.

Molenaar, S. D., Saha, P., Mol, A. R., Sleutels, T. H., Ter Heijne, A., and Buisman, C. J. (2017). Competition between methanogens and acetogens in biocathodes: a comparison between potentiostatic and galvanostatic control. Int. J. Mol. Sci. 18:204. doi: 10.3390/ijms18010204

Monod, J. (1949). The growth of bacterial cultures. Annu. Rev. Microbiol. 3, 371-394.

Morgado, L., Paixão, V. B., Schiffer, M., Pokkuluri, P. R., Bruix, M., and Salgueiro, C. A. (2012). Revealing the structural origin of the redox-Bohr effect: the first solution structure of a cytochrome from Geobacter sulfurreducens. Biochem. J. 441, 179-187. doi: 10.1042/bj20111103

Myint, A. A., Lee, W., Mun, S., Ahn, C. H., Lee, S., and Yoon, J. (2010). Influence of membrane surface properties on the behavior of initial bacterial adhesion and biofilm development onto nanofiltration membranes. Biofouling 26, 313-321. doi: 10.1080/08927010903576389

Nagarajan, H., Sahin, M., Nogales, J., Latif, H., Lovley, D. R., Ebrahim, A., et al. (2013). Characterizing acetogenic metabolism using a genome-scale metabolic reconstruction of Clostridium ljungdahlii. Microb. Cell Fact. 12:118. doi: 10. 1186/1475-2859-12-118

Nevin, K. P., Hensley, S. A., Franks, A. E., Summers, Z. M., Ou, J., Woodard, T. L., et al. (2011). Electrosynthesis of organic compounds from carbon dioxide is catalyzed by a diversity of acetogenic microorganisms. Appl. Environ. Microbiol. 77, 2882-2886. doi: 10.1128/aem.02642-10

Nevin, K. P., Woodard, T. L., Franks, A. E., Summers, Z. M., and Lovley, D. R. (2010). Microbial Electrosynthesis: feeding microbes electricity to convert carbon dioxide and water to multicarbon extracellular organic compounds. mBio 1:e00103-10.

Nielsen, C. F., Lange, L., and Meyer, A. S. (2019). Classification and enzyme kinetics of formate dehydrogenases for biomanufacturing via $\mathrm{CO} 2$ utilization. Biotechnol. Adv. 37:107408. doi: 10.1016/j.biotechadv.2019.06.007

Pandit, A. V., and Mahadevan, R. (2011). In silico characterization of microbial electrosynthesis for metabolic engineering of biochemicals. Microb. Cell Fact. 10:76. doi: 10.1186/1475-2859-10-76

Pavlostathis, S. G., and Giraldo-Gomez, E. (1991). Kinetics of anaerobic treatment. Water Sci. Technol. 24, 35-59.

Pérez, J., Picioreanu, C., and van Loosdrecht, M. (2005). Modeling biofilm and floc diffusion processes based on analytical solution of reaction-diffusion equations. Water Res. 39, 1311-1323. doi: 10.1016/j.watres.2004.12.020

Picioreanu, C. I, Head, M., Katuri, K. P., van Loosdrecht, M. C., and Scott, K. (2007). A computational model for biofilm-based microbial fuel cells. Water Res. 41, 2921-2940. doi: 10.1016/j.watres.2007.04.009

Picioreanu, C., van Loosdrecht, M. C., Curtis, T. P., and Scott, K. (2010). Model based evaluation of the effect of $\mathrm{pH}$ and electrode geometry on microbial fuel cell performance. Bioelectrochemistry 78, 8-24. doi: 10.1016/j.bioelechem.2009. 04.009

Prévoteau, A., Carvajal-Arroyo, J. M., Ganigué, R., and Rabaey, K. (2020). Microbial electrosynthesis from $\mathrm{CO} 2$ : forever a promise? Curr. Opin. Biotechnol. 62, 48-57. doi: 10.1016/j.copbio.2019.08.014

Raes, S. M., Jourdin, L., Buisman, C. J., and Strik, D. P. (2017). Continuous long-term bioelectrochemical chain elongation to butyrate. ChemElectroChem 4, 386-395. doi: $10.1002 /$ celc. 201600587

Rauch, W., Vanhooren, H., and Vanrolleghem, P. A. (1999). A simplified mixedculture biofilm model. Water Research 33, 2148-2162. doi: 10.1016/s00431354(98)00415-1

Ribes, J., Keesman, K., and Spanjers, H. (2004). Modelling anaerobic biomass growth kinetics with a substrate threshold concentration. Water Res. 38, 45024510. doi: 10.1016/j.watres.2004.08.017

Roels, J. (1983). Energetics and Kinetics in Biotechnology. Amsterdam, NY: Elsevier Biomedical Press.

Roghair, M., Liu, Y., Adiatma, J. C., Weusthuis, R. A., Bruins, M. E., Buisman, C. J., et al. (2018). Effect of n-caproate concentration on chain elongation and competing processes. ACS Sustain. Chem. Eng. 6, 7499-7506. doi: 10.1021/ acssuschemeng. 8 b00200

Rojas, M. d. P. A, Zaiat, M., González, E. R., De Wever, H., and Pant, D. (2021). Enhancing the gas-liquid mass transfer during microbial electrosynthesis by the variation of CO2 flow rate. Process Biochem. 101, 50-58. doi: 10.1016/j.procbio. 2020.11.005

Rosa, L. F. M., Hunger, S., Zschernitz, T., Strehlitz, B., and Harnisch, F. (2019). Integrating electrochemistry into bioreactors: effect of the upgrade kit on mass transfer, mixing time and sterilisability. Front. Energy Res. 7:98. doi: 10.3389/ fenrg.2019.00098

Russell, J. (1992). Another explanation for the toxicity of fermentation acids at low pH: anion accumulation versus uncoupling. J. Appl. Bacteriol. 73, 363-370. doi: 10.1111/j.1365-2672.1992.tb04990.x

Russell, J. B. (2007). The energy spilling reactions of bacteria and other organisms. J. Mol. Microbiol. Biotechnol. 13, 1-11. doi: 10.1159/000103591

Salimijazi, F., Kim, J., Schmitz, A. M., Grenville, R., Bocarsly, A., and Barstow, B. (2020). Constraints on the efficiency of engineered electromicrobial production. Joule 4, 2101-2130. doi: 10.1016/j.joule.2020.08.010

Schuchmann, K., and Müller, V. (2013). Direct and reversible hydrogenation of $\mathrm{CO} 2$ to formate by a bacterial carbon dioxide reductase. Science 342, 1382-1385. doi: $10.1126 /$ science. 1244758

Schuchmann, K., and Müller, V. (2014). Autotrophy at the thermodynamic limit of life: a model for energy conservation in acetogenic bacteria. Nat. Rev. Microbiol. 12:809. doi: $10.1038 /$ nrmicro3365 
Tijhuis, L., Van Loosdrecht, M. C., and Heijnen, J. v. (1993). A thermodynamically based correlation for maintenance Gibbs energy requirements in aerobic and anaerobic chemotrophic growth. Biotechnol. Bioeng. 42, 509-519. doi: 10.1002/ bit. 260420415

Vander Wielen, L., Van Buel, M., Straathof, A., and Luyben, K. C. A. (1997). Modelling the enzymatic deacylation of penicillin G: equilibrium and kinetic considerations. Biocatal. Biotransformation 15, 121-146. doi: 10.3109/ 10242429709003614

Vassilev, I., Hernandez, P. A., Batlle-Vilanova, P., Freguia, S., Krömer, J. O., Keller, J. r., et al. (2018). Microbial electrosynthesis of isobutyric, butyric, caproic acids, and corresponding alcohols from carbon dioxide. ACS Sustain. Chem. Eng. 6, 8485-8493. doi: 10.1021/acssuschemeng.8b00739

Váchová, L. e., and Palková, Z. (2005). Physiological regulation of yeast cell death in multicellular colonies is triggered by ammonia. J. Cell Biol. 169, 711-717. doi: $10.1083 /$ jcb. 200410064

Weiss, R. F. (1974). Carbon dioxide in water and seawater: the solubility of a non-ideal gas. Mar. Chem. 2, 203-215. doi: 10.1016/0304-4203(74)90015-2

Wiesenborn, D. P., Rudolph, F. B., and Papoutsakis, E. T. (1988). Thiolase from Clostridium acetobutylicum ATCC 824 and its role in the synthesis of acids and solvents. Appl. Environ. Microbiol. 54, 2717-2722. doi: 10.1128/aem.54.11. 2717-2722.1988

Xavier, J. B., Picioreanu, C., and Van Loosdrecht, M. C. (2005). A framework for multidimensional modelling of activity and structure of multispecies biofilms. Environ. Microbiol. 7, 1085-1103. doi: 10.1111/j.1462-2920.2005 00787.x

Zeng, A.-P., and Deckwer, W.-D. (1995). A kinetic model for substrate and energy consumption of microbial growth under substrate-sufficient conditions. Biotechnol. Prog. 11, 71-79. doi: 10.1021/bp00031a010

Zeng, Y., Choo, Y. F., Kim, B.-H., and Wu, P. (2010). Modelling and simulation of two-chamber microbial fuel cell. J. Power Sour. 195, 79-89. doi: 10.1016/j. jpowsour.2009.06.101

Zheng, X.-J., and Yu, H.-Q. (2005). Inhibitory effects of butyrate on biological hydrogen production with mixed anaerobic cultures. J. Environ. Manag. 74, 65-70. doi: 10.1016/j.jenvman.2004.08.015

Conflict of Interest: The authors declare that the research was conducted in the absence of any commercial or financial relationships that could be construed as a potential conflict of interest.

Copyright (c) 2021 Cabau-Peinado, Straathof and Jourdin. This is an open-access article distributed under the terms of the Creative Commons Attribution License (CC BY). The use, distribution or reproduction in other forums is permitted, provided the original author(s) and the copyright owner(s) are credited and that the original publication in this journal is cited, in accordance with accepted academic practice. No use, distribution or reproduction is permitted which does not comply with these terms. 